\title{
Transitioning Coal Power Plants to Nuclear Power
}

George Griffith

Idaho National Laboratory

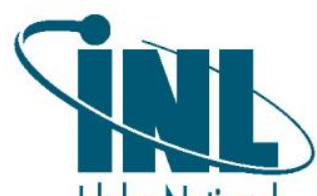

Idaho National Laboratory 


\section{DISCLAIMER}

This information was prepared as an account of work sponsored by an agency of the U.S. Government. Neither the U.S. Government nor any agency thereof, nor any of their employees, makes any warranty, expressed or implied, or assumes any legal liability or responsibility for the accuracy, completeness, or usefulness, of any information, apparatus, product, or process disclosed, or represents that its use would not infringe privately owned rights. References herein to any specific commercial product, process, or service by trade name, trademark, manufacturer, or otherwise, does not necessarily constitute or imply its endorsement, recommendation, or favoring by the U.S. Government or any agency thereof. The views and opinions of authors expressed herein do not necessarily state or reflect those of the U.S. Government or any agency 


\title{
Transitioning Coal Power Plants to Nuclear Power
}

\author{
George Griffith \\ Idaho National Laboratory \\ December 2021
}

\section{Idaho National Laboratory Reactor System Design and Analysis Idaho Falls, Idaho 83415}

http://www.inl.gov

\author{
Prepared for the \\ U.S. Department of Energy \\ Office of Nuclear Energy \\ Under DOE Idaho Operations Office \\ Contract DE-AC07-05ID14517
}


Page intentionally left blank 


\section{SUMMARY}

Across the United States, communities and the energy industry are working to decarbonize their energy generation and consumption and are implementing actions to achieve zero-carbon-emission goals. This is a reflection of the Nation's commitment to carbon reduction and supporting the policies of the Federal and State governments. An increasing number of coal power plant (CPP) retirements has been seen across the Nation to support lower carbon plans. Transitions from coal to gas fuel have dominated the Nation's energy landscape over the past decade and allowed the Nation to reduce its carbon emissions, there is a continued desire to further reduce carbon emission from energy portfolios as the Nation works to decarbonize its electricity and energy generation. As more CPPs are retired, a reliable and affordable zero-emission power replacement is needed. Nuclear power is a viable dispatchable and clean source of energy that can replace a $\mathrm{CPP}$.

Beyond the functional replacement of the power being provided to the grid, a nuclear power plant (NPP) approximates the staffing and economic benefits of a retired CPP. A new NPP will employ similar numbers of professional employees. The operating NPP will also provide the benefits of a long-term continuing tax base to support the local community.

There is a large near-term potential to transition recently retired and operating CPPs with NPPs. Decommissioning coal plants is ongoing and accelerating for last decade when almost half of the nation's 400 CPPs were retired. Going forward, retirements of larger and newer plants are to be expected. Retaining the intrinsic power-producing value of the site should provide increased incentive to use these former CPPs.

There are many options for replacing coal power generation with different technical and socioeconomic considerations at each CPP. The power plant function can be replaced; however, the significant technical differences between coal and NPP make nuclear repowering a CPP challenging. Fully removing the coal plant and replacing it with a nuclear plant is the most understood path forward in terms of being able to meet zero-carbon goals. Each coal site would require assessment to determine the viability of the coal-to-nuclear transition. The type and number of any equipment retained will depend on the particulars of the retired coal plant and the design features of the new nuclear plant.

Repowering a site by replacing the heat producing coal boiler with a heat producing nuclear reactor and retaining the existing power-producing technologies would require specialized equipment and analysis.

Given the new generation of highly capable, safe, and economic NPPs being developed, transitioning CPPs to zero-carbon production is ever more promising. The purpose of this report is to provide information to utilities and other stakeholders in their consideration of replacing CPP with NPP. Near-term issues that should be considered and are discussed include energy generating basics, factors in replacing a CPP with a NPP, matching a NPP with the CPP, decommissioning the $\mathrm{CPP}$, and considering siting conditions.

These factors are being considered in the near term. Long-range changes in the markets, regulation, and technology may significantly improve the transition 
from coal to nuclear power. As CPPs are converted to NPPs the experience gained can optimize the transition planning and deployment, greatly reducing time and expense.

This report is not intended to draw a conclusion on any specific CPP. To further the understanding of a coal-to-nuclear power transition, it is suggested that more detailed studies of specific power plants be performed. CPPs evaluated could come with different power levels, ages, markets structures, and regions of the country. A methodology to evaluate a CPP site is needed going forward. This consistent methodology would also enable experience gained from one proposed project to another. Comparing implementation details between CPP transition projects, both commonalities and factors that will have to be uniquely evaluated can be identified. Studies of market competitiveness and integrated energy systems (IESs) can be studied in conjunction with or separately from the more detailed transition studies. The option of included industrial processes and other generation resources will allow more optimized site solutions. Once necessary factors in a successful transition are understood optimization of regulation and design can be developed. 


\section{CONTENTS}

SUMMARY

ACRONYMS viii

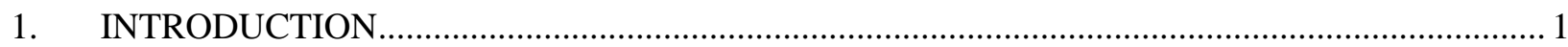

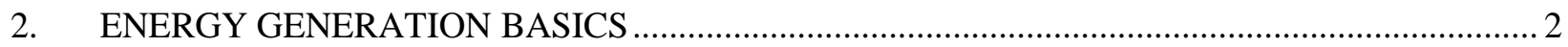

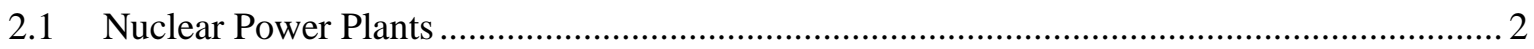

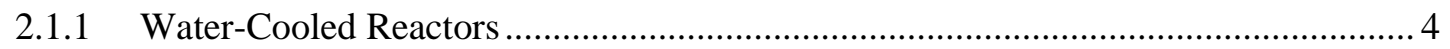

2.1.2 Non-Water-Cooled Reactors ........................................................................... 4

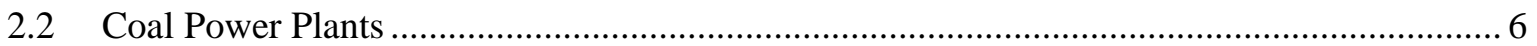

3. CONSIDERATIONS FOR REPLACING CPPs WITH NPPs …............................................. 9

3.1 Coal Boiler and Nuclear Steam Generator ....................................................................... 9

3.2 Coal and Nuclear Power Plants Technology.................................................................. 11

3.2.1 Decommissioning CPPs: Preserving Transmission Connection ................................ 12

3.2.2 Retaining Power-Block Infrastructure: Reusing Steam Supply .............................. 13

3.2.3 Repowering Options: Indirect Connection to Steam Supply ................................... 14

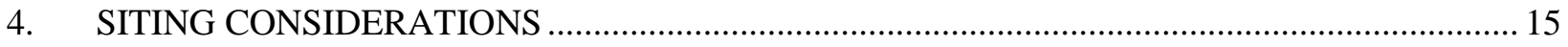

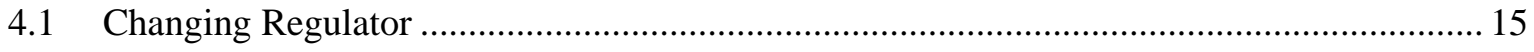

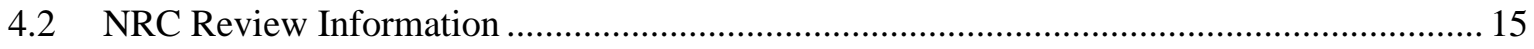

4.3 Environmental Conditions Requirements ..................................................................... 15

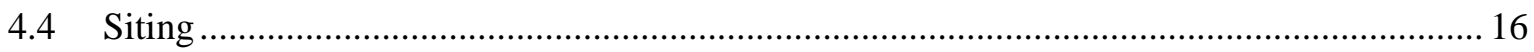

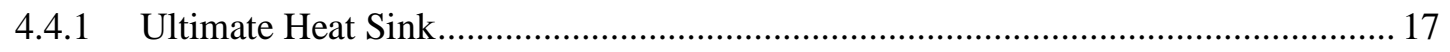

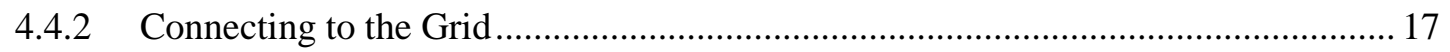

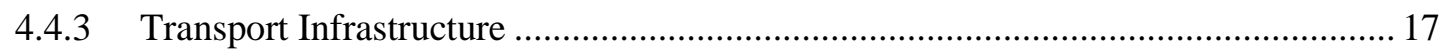

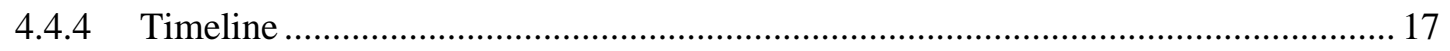

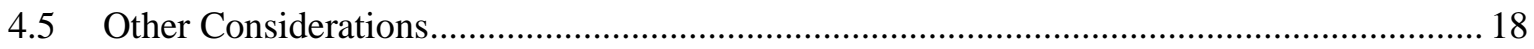

4.5.1 Plant Ownership and Government Support....................................................... 18

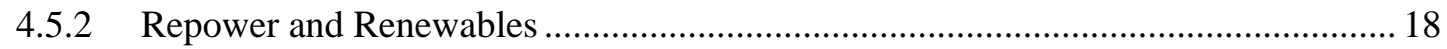

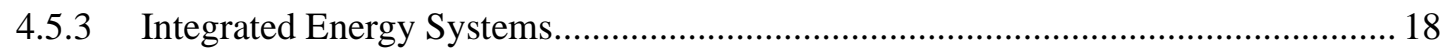

4.6 Workforce and Community-Related Topics ..................................................................... 19

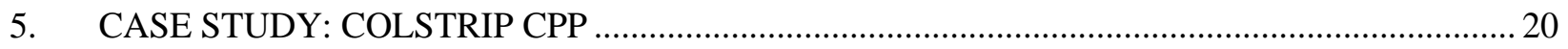

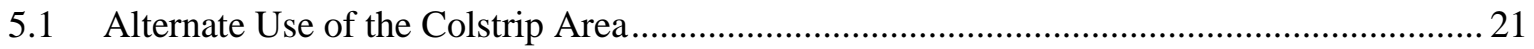

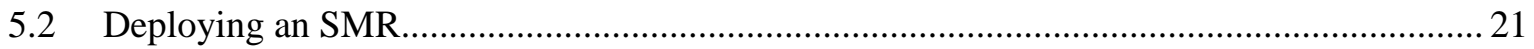

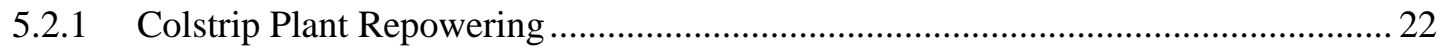

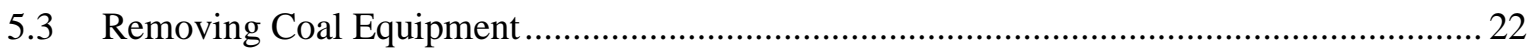

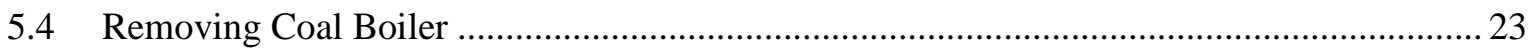

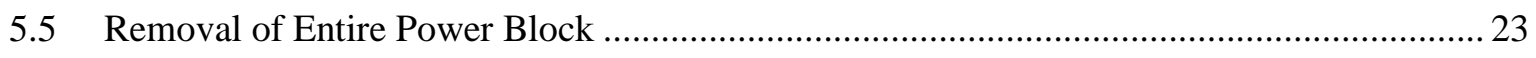

5.6 Starting with a Decommissioned and Cleared Site ......................................................... 24 


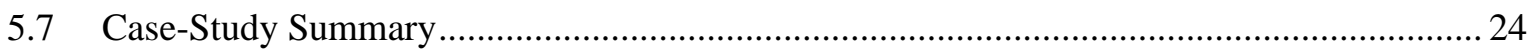

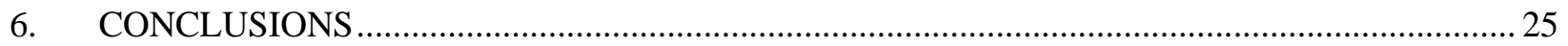

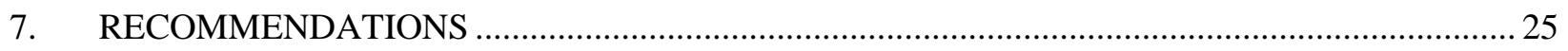

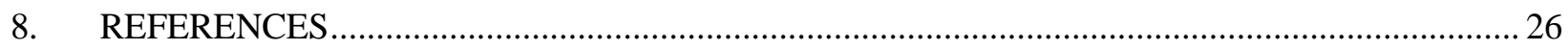

FIGURES

Figure 1:Simplified Diagram of Nuclear Power Plant ............................................................................ 3

Figure 2: Currently Operating Coal Plants in United States ................................................................ 7

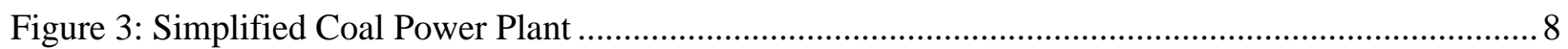

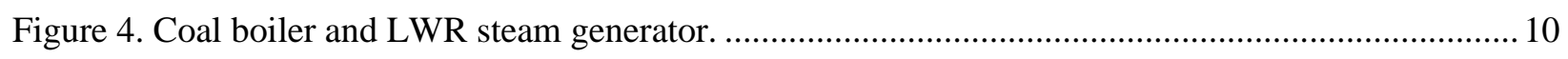

Figure 5. HTGR Fort St. Vrain steam-generator diagram. .............................................................. 11

Figure 6. Colstrip Power Plant area, showing large area of the CPP system..........................................20

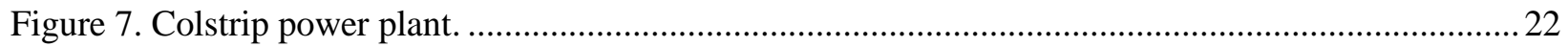

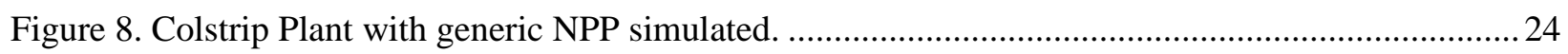

\section{TABLES}

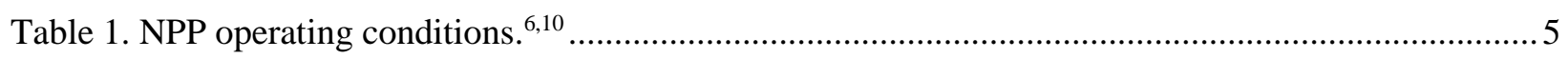

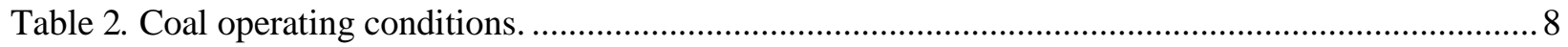

Table 3. Reduced costs for 610 MWe combined cycle CPP (2009 dollars). ${ }^{12}$...................................... 13 
Page intentionally left blank 


\section{ACRONYMS}

CPP coal power plant

CCR coal combustion residuals

D\&D Decommissioning, and Demolition

DOE Department of Energy

DOE-ID Department of Energy Idaho Operations Office

EA environmental assessment

ESP early site permit

HTGR high-temperature, gas-cooled reactor

IES integrated energy system

LMR liquid-metal reactor

MATS EPA Mercury and Air Toxics Standards

MSR molten-salt reactor

NE (Office of) Nuclear Energy

NEPA National Environmental Policy Act

NPP nuclear power plant

NRC Nuclear Regulatory Commission

SMR small modular reactor 
Page intentionally left blank 


\section{Transitioning Coal Power Plants to Nuclear Power}

\section{INTRODUCTION}

The purpose of this report is to provide information to energy professionals (utilities, energy planners, commissioners) in the consideration of transitioning coal plants to nuclear power and includes a list of attributes to consider when determining the viability of a coal plant for nuclear power transition. This report examines the market opportunities and benefits for transitioning a site from coal to nuclear and the technical and logistical considerations for undertaking such replacement.

Many large U.S. power companies are setting zero- or low-carbon emission goals with varying compliance dates. Companies approach this goal in different ways, including by retiring coal power plants (CPPs). ${ }^{1}$ CPPs have difficulty competing in the current energy market, and new global emphasis on reducing carbon emissions will likely increase the pressure on CPPs. Decommissioning coal plants has been ongoing for last decade when almost half of all CPPs closed resulting in the retirement of 473 plants. ${ }^{2}$ The model developed by National Bureau of Economic Research to predict coal plant retirements calculates that three-quarters of the nation's coal generation capacity will retire in the next 20 years with most of those retirements occurring within the next 5 years. ${ }^{3}$

Of the approximately 200 CPPs shut down between 2010 and 2019, the average power capacity was 200 MWe. The plants retired in 2010 were, on average, 20 years older than of those retired in 2018. The average age of plants being retired is now comparable to the age of the operating fleet. The average power of retired plants has also tended to increase over the years, and the average power level in the current operating CPP fleet is more than 350 MWe. These plant retirements appear to be removing older, lowerpower units, preferentially increasing the viability of the remaining fleet. ${ }^{4}$ Going forward, retirements of larger and newer CPPs are to be expected, and the newer plants will have newer components and potentially higher value in their relatively new equipment. Retaining the increased plant value and the intrinsic value of the site should provide increasing incentive to repower, rather than retire the plants.

Some coal plants have been converted to natural gas to reduce production costs, reduce carbon emissions, and avoid required emissions upgrades by using a more-efficient heat source. ${ }^{5}$ However, with continued pressure to reach zero carbon emissions will be important to address the carbon emitted from natural gas plants. This repowering approach to improving a coal plant can be further extended by changing to a nuclear power plant (NPP) that uses a fundamentally different source of energy that has no direct carbon emissions. Given the previous discussion about the pace of coal plant retirements, it is important to consider converting coal to nuclear now enabling high probabilities to reach zero-carbon emission goal, as well as the benefit to the local community of retaining a similar industrial base. It is possible for a natural gas plant with carbon capture and sequestration (CCS) to achieve similar goals in the next decade as well and is dependent on the continued innovation of CCS technology. The last factor to consider is the approximate lifetime of the assets being considered: today's nuclear plants are licensed for up to 80 years of operation, whereas the expected lifetime of a natural gas plant is about 30 years.

The technical differences between CPPs and NPPs that exist must be considered to identify the right candidate plants and sites for such a transformation. For example, the different operating conditions, safety approaches, and regulation should be fully evaluated. The longer operating lifetime and no direct carbon emission of nuclear power make this kind of transition a more complete and beneficial solution. However, it may become a more complex task and is the focus of this report. A required nuclear license has detailed evaluations of how the site and reactor interact to ensure safety. The evaluations account for broad effects on the community, environment, and public safety. The appeal of an existing CPP as a new NPP site extends beyond the equipment involved. The opportunity to continue the existing capabilities of the local workforce and sustain communities that would be decimated by plant retirements are further benefits. 
The potential reuse of CPP sites as locations for carbon-free nuclear power generation reveal a spectrum of potential options. There could be a variety of replacement options, from replacing only the heat source to replacing the entire plant. Three options are often discussed when considering a coal to nuclear transition (1) Reusing the electrical switchyard and grid connection (2) Direct connection and reuse of the steam system or (3) Indirect connection and reuse of the steam system.

A new generation of NPPs is being designed that have increased safety, lower construction costs, faster deployment, and easier siting requirements making them more attractive to replace CPPs than conventional large NPPs. The new reactor designs use technology to operate efficiently at lower reactor power, incorporate simplicity to improve operations and maintenance, provide high levels of safety, include integrated designs and modular reactors. These new design features address many of the issues inherent in deploying large conventional NPPs and work individually and collectively to allow higher levels of safety and more-economical operation.

\section{ENERGY GENERATION BASICS}

CPPs and traditional NPPs employ broadly similar systems in order to function on the electrical grid. Both types of plant use a heat source to generate steam. A steam conversion system feeds, the steam to a turbine that connects to the generator to create the electricity. Finally, a transmission system delivers the electricity to the grid, where it ultimately gets redistributed to consumers. Traditional power plants also require a sufficient water supply to support the generation of steam at the heat source, as well as the necessary condensing during the steam conversion process.

Of these three systems, the heat source is the most different between a nuclear power plant and a coal plant. The steam conversion equipment and transmission system have similarities but may have some important differences on closer examination. For example, electrical-generation equipment at a CPP and a NPP are similar: power lines, transformers, and electrical-conditioning systems. A NPP may need highquality grid connections to power equipment in the plant from offsite. Future NPPs tend to depend less on offsite power than do current NPPs. The broad similarities immediately diverge, however, as the systems are more closely examined, and new NPP designs are considered. These differences drive what can and cannot be accomplished in a transition from a CPP to a NPP.

A high-level review of these differences and the work to resolve these differences is provided to frame the various power transition options.

\subsection{Nuclear Power Plants}

The current fleet of nuclear reactors generate nearly $20 \%$ of US electricity each year and $55 \%$ of carbon-free electricity in the US. All are large, water-cooled reactors. ${ }^{6,7}$ Nuclear power has been evolving rapidly in recent years, and new technology and designs are intended to make nuclear power easier to deploy and operate. These updates enhance the opportunity replace a CPP with a NPP. The U.S. private sector has been developing a spectrum of nuclear power options that could be considered in transitioning from a CPP. These new reactor designs are generally smaller, more flexible, inherently safer, and less expensive than current NPPs. These design innovations better match coal-to-nuclear transition needs with a power grid that are more heavily supplied by intermittent renewables sources such as solar and wind.

NPPs use uranium fission to create chain reactions that generate heat. Uranium fission does not require combustion to create heat; thus, it generates no carbon emissions and provides an extraordinarily high energy density. One uranium fuel pellet, approximately a third of an inch in diameter and half an inch long, creates as much energy as one ton of coal. ${ }^{8}$ NPPs produce both low and high-level radioactive waste as a result of these power-producing fissions. Low-level wastes are low concentrations of operating material from the reactor that can be disposed of away offsite. High-level waste is related to the nuclear fuel that has been permanently discharged from the reactor. This high-level waste is stored in the spentfuel storage pool of the reactor, where it is shielded and allowed to cool by decay of fission products. 
Once the fuel has cooled, it can be placed into long-term dry-cask storage at the NPP site. Means for final disposition of the used fuel are being developed by the Federal government. Current reactors refuel only every 18-24 months during maintenance outages, instead of the continuous fueling typical of a CPP.

In current U.S. commercial reactors, uranium fission generates heat, raising the temperature of water and ultimately generating steam to drive a turbine and generator. A simplified schematic of a nuclear power plant is shown in Figure 1. Current commercial reactors produce around 1000 MWe for up to two years, at which point approximately a third of the uranium fuel must be replaced. The new generation of reactors being introduced features a wide variety of sizes and longer refueling schedules some ranging up to 20 years.

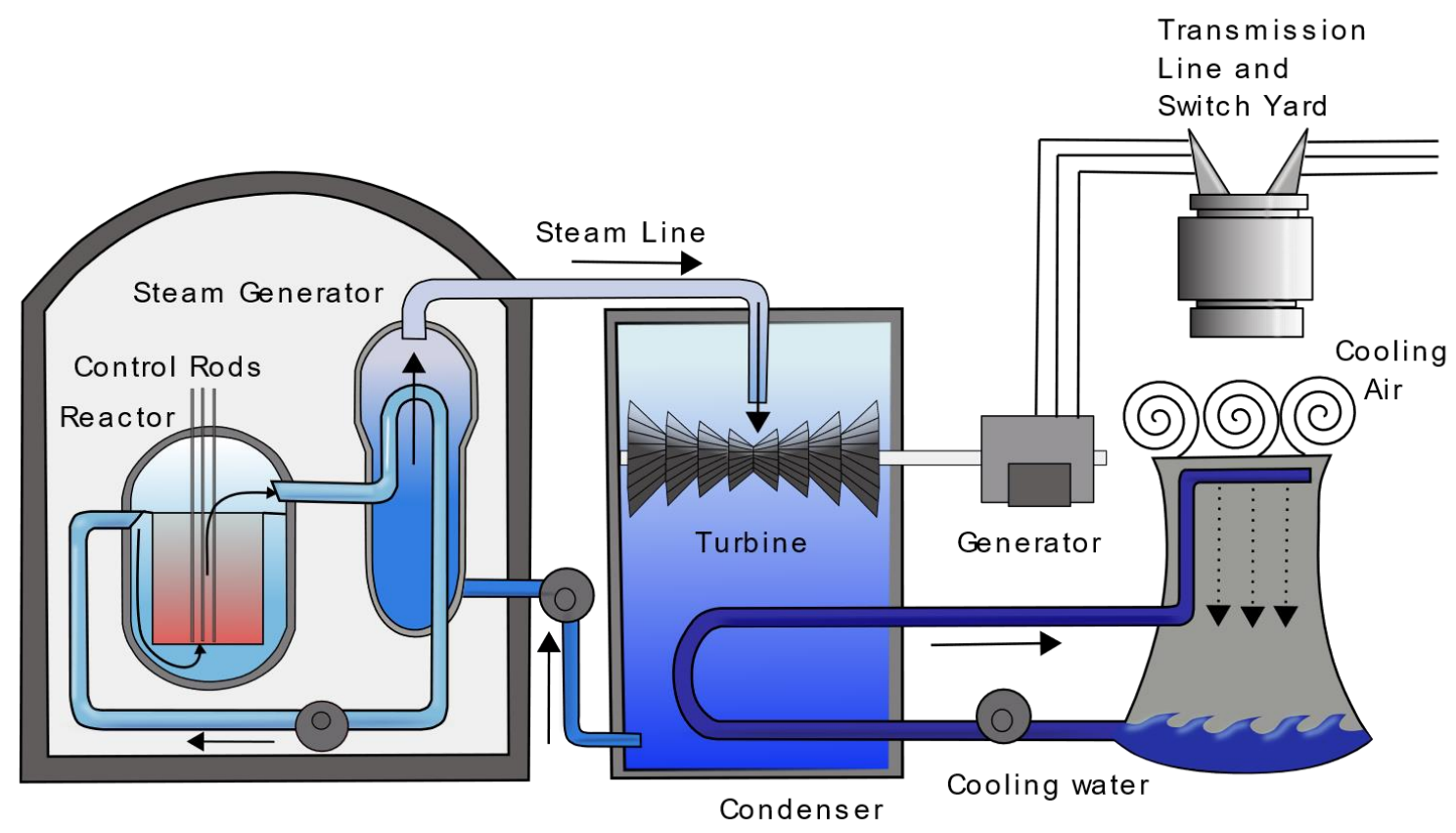

Figure 1:Simplified diagram of nuclear power plant.

When the nuclear fuel has completed its operation in the reactor, it is discharged and then stored locally in controlled conditions to keep it safe and stable. After many years of storage, the bundles will be less radioactive allowing the fuel to be stored locally, but away from the reactor. In light-water reactors (LWRs) the fuel is moved from the spent-fuel storage pool to dry-cask storage. Ultimately it is anticipated that the fuel will reside in permeant geologic storage. ${ }^{9}$

All nuclear fission produces neutrinos, neutrons, and fission products. Fission products are very energetic and deposit their kinetic energy as heat in the fuel. Increased heat from additional fissions generates enough power to generate electricity and generates additional fission products and more resultant nuclear waste. One way to reduce nuclear waste is to more-efficiently use generated heat to make more electricity for the same number of fissions and amount of waste. Advanced reactors are generally designed to operate at higher temperatures and higher electrical efficiencies that reduce relative amounts of nuclear waste. Reactors designed to use fast neutrons can be used to eliminate some of the long-lived radioactive material, helping reduce the burden of nuclear waste.

New reactor designs are also more easily and reliably deployed. Reactor vendors look to deploy new commercial-reactor technology beyond the traditional large, water-cooled reactor designs. Modern reactor designs demonstrate higher levels of passive safety and higher operating temperatures, enabling lower cost and higher efficiency. Higher operating temperatures can also allow the reactors to produce heat directly for industrial uses including decarbonizing processes such as hydrogen generation. Advanced 
nuclear fuels provide inherent robustness, better trapping fission products in the fuel, increasing safety, and allowing more-flexible siting processes of the reactor.

The following sections list some of the technology and reactor performance in the newest planned reactors. ${ }^{10}$ More details are available from the U.S. Energy Information Administration, ${ }^{11}$ World Nuclear Association, ${ }^{12}$ Nuclear Energy Institute, ${ }^{13}$ and the U.S. Department of Energy. ${ }^{14}$

\subsubsection{Water-Cooled Reactors}

Globally, water-cooled reactors are the most operated nuclear reactors and are referred to as light water reactors (LWRs). LWRs currently make up the entire U.S. fleet of nuclear power reactors. The U.S. fleet is made up of two types of LWR: pressurized water reactors (PWRs) and boiling water reactors (BWRs). The typical footprint for these reactors is about 600 acres. These reactors provide $20 \%$ of the U.S. electric production and $50 \%$ of its carbon-free power.

New water-cooled reactors are being designed to take advantage of the extensive operating experience of the current generation of operating reactors. Advances in design and technology allow increased levels of safety and improved economics. The advanced water-cooled reactors are easier and less expensive to deploy because they tend to be smaller and factory built, unlike the current fleet of plants. Advanced water-cooled reactors are the first small modular reactors (SMRs), although not all SMRs are water-cooled.

\subsubsection{Non-Water-Cooled Reactors}

Nuclear reactors that use coolants other than water offer potential benefits in some applications. Alternate coolants allow the reactor to operate at lower pressure which simplifies parts of the design. Lower reactor pressures also allow the reactor to operate at higher temperatures, allowing increased thermal efficiency and the potential to provide heat for non-power industrial applications.

\subsubsection{Salt- and sodium-cooled reactors}

Halogen salts that melt at relatively low temperatures in a reactor allow higher temperatures and lower pressures than typical water-cooled reactors. Molten salt has a good heat-transfer mechanism. Molten salts display low corrosion rates when designed with the correct nuclear materials. Molten-salt reactors (MSRs) are well suited for high-temperature operation. Molten salts can be used for heat storage, allowing MSR designs to easily incorporate heat-storage systems by increasing the volume of heated salt. A molten-salt heat-storage system can create a loose connection between nuclear safety-related system and the balance of the coal plant systems, possibly simplifying the overall project.

A liquid metal, like sodium or lead, also allows for relatively high temperatures in low-pressure systems. Sodium-cooled reactors are a well-established technology. Carefully designed, the liquid-metalcooled reactor (LMR) offer inherent safety features and unique operating performance. ${ }^{15}$ LMRs are traditionally operated without slowing neutrons, which results in more-efficient fuel use.

\subsubsection{High-temperature gas-cooled reactors}

Reactors cooled with helium, moderated by carbon, and using advanced multilayer fuel have shown the potential to operate inherently safely and economically. The carbon moderator replaces water as the material that slows neutrons to increase fission efficiency in the reactor. Because carbon can safely operate at high temperatures and requires no pressurization, a high-temperature gas-cooled reactor (HTGR) can operate at both high temperatures and low pressures. An HTRG can operate at temperatures that match superheated CPP temperatures, allowing at least the potential to operate using CPP turbine and steam equipment. Modular and single unit designs exist at a variety of power levels.

\subsubsection{Microreactors}


Microreactors differ from the previously described reactors, which were defined by the technology that allows the reactor to maintain a chain reaction. Microreactors, as a class, are defined by their small power output, generally less than a few tens of megawatts electrical, and very robust designs.

Microreactors can include versions of any of the previously described reactors as well as unique forms allowed by their small size. Test and research reactors are often small, but do not include the robust designs and transportability of some microreactors. Microreactors generally entail minimal accident consequences because of their small size and limited potential to release radioactive materials.

Microreactors are designed to be factory built (as opposed to larger reactors which are all individually constructed), potentially autonomous, and portable. These properties allow microreactors to support applications in remote locations for microgrids and industrial applications that are not practical by larger conventional plants.

Although there are a variety of nuclear reactors, Table 1 includes a summary of operating parameters of select conventional and advanced reactors. A variety of reactor sizes are available and multiple units can typically be combined into a single nuclear power plant. Higher operating temperatures provide higher thermal efficiency. Non-water-cooled reactors are not tied to higher pressures to reach higher temperatures.

Table 1. NPP operating conditions. ${ }^{10,18}$

\begin{tabular}{|l|l|c|c|c|c|c|}
\hline Reactor Type & Nuclear Power Plant Design & $\begin{array}{c}\text { Power } \\
\mathrm{MW}_{\mathrm{e}}\end{array}$ & $\begin{array}{c}\text { Operating } \\
\text { Temperature } \\
{ }^{\circ} \mathrm{C}\end{array}$ & $\begin{array}{c}\text { Primary } \\
\text { Pressure } \\
\mathrm{MPa}\end{array}$ & $\begin{array}{c}\text { Full Plant } \\
\text { Footprint } \\
\text { acres }\end{array}$ & $\begin{array}{c}\text { Thermal } \\
\text { Efficiency } \\
\%\end{array}$ \\
\hline Water-cooled & GE-Hitachi, BWRX-300 & 300 & 287 & 7.2 & 22 & 33 \\
\hline Water-cooled & $\begin{array}{l}\text { NuScale Power, NuScale } \\
\text { Reactor }\end{array}$ & 77 & 300 & 13.8 & 35 & 30 \\
\hline Water-cooled & Holtec SMR-160 & 160 & 316 & 15.5 & 5 & 30 \\
\hline $\begin{array}{l}\text { Molten-Salt } \\
\text { Fast Reactor }\end{array}$ & $\begin{array}{l}\text { TerraPower, Molten Chloride } \\
\text { Fast Reactor }\end{array}$ & 780 & 755 & & $166^{16}$ & \\
\hline MSR & $\begin{array}{l}\text { Terrestrial Energy, Integral } \\
\text { Molten Salt Reactor }\end{array}$ & 195 & 600 & 0.4 & $177^{17}$ & 44 \\
\hline MSR & Moltex, Stable Salt Reactor & 400 & 700 & 0.1 & & 40 \\
\hline MSR & Kairos Power, KP-FHR & 140 & 650 & 0.2 & & 44 \\
\hline MSR & $\begin{array}{l}\text { TerraPower/GE Hitachi, } \\
\text { Natrium }\end{array}$ & 345 & 540 & & & \\
\hline HTGR & X-energy, Xe-100 & 80 & 565 & 6 & 22 & 41 \\
\hline HTGR & $\begin{array}{l}\text { General Atomics, Energy } \\
\text { Multiplier Module }\end{array}$ & 265 & 850 & 13.3 & & 53 \\
\hline HTGR & General Atomics, SC-HTGR & 272 & 750 & 6 & & 43 \\
\hline Microreactor & Oklo Aurora & 1.5 & 500 & N/A & $<1$ & 37.5 \\
\hline Microreactor & $\begin{array}{l}\text { BWXT, BWXT Advanced } \\
\text { Reactor }\end{array}$ & 17 & 750 & N/A & & \\
\hline Microreactor & Westinghouse, eVinciTM & 5 & 750 & N/A & $<1$ & 29 \\
\hline Microreactor & $\begin{array}{l}\text { Ultra Safe Nuclear } \\
\text { Corporation, Micro Modular } \\
\text { Reactor }\end{array}$ & 5 & 630 & 3 & & 40 \\
\hline
\end{tabular}


One of the new nuclear technologies being developed is the SMR, a reactor designed to reach the market and economically and safely make power. To reduce the direct cost and ease connection to the grid, SMR capacities are limited to $300 \mathrm{MWe}$, which is less than one-third the size of conventional NPP, but similar in output to many conventional coal boilers. This reduces the physical size and simplifies manufacturing, even allowing for factory assembly. SMRs are also typically designed to be very simple and to use passive systems to further reduce complexity and facilitate high levels of safety. Using multiple modular, small, and safe reactors allows the NPP to be scaled to meet local needs and support power generation for applications beyond electricity generation. Increased safety reduces the size of emergency-planning zones which allows easier siting. These technical advancements provide more certainty in the new NPP deployment time and costs. The collective benefit from SMR design features promises low-cost, safe operation. These attributes make SMRs and advanced reactors of particular interest when considering CPP-to-NPP conversion.

The reduced size of the SMR allows new and flexible deployment options. Physically smaller reactors use less material in construction and allow for increased factory fabrication, simplifying and speeding their deployment. Smaller reactors also have reduced nuclear-material inventories, making siting easier. Reduced nuclear-material inventories demonstrate higher levels of safety and improve the overall efficiency of operation.

Integrated reactor designs have all reactor components combined into a single pressure vessel. This simplifies design and increases safety by reducing piping, valves, and equipment. Integrated designs also tend to incorporate passive features, like natural circulation, to further simply design and operation. ${ }^{18}$

\subsection{Coal Power Plants}

Although there are multiple generations and technologies, CPPs produce power with significantly different technology and components than a NPP. In a CPP, pulverized coal fires a boiler to create continuous combustion. The burning coal radiates heat directly to steel tubes filled with water and steam and transferring heat to the tubes in other parts of the boiler through convection. The steam is used to spin a turbine to drive a generator. Optimizing heat transfer and steam creation allows efficient use of the coal's energy in the turbine. The U.S. current fleet is more than 300 CPPs, each usually equipped with more than one coal boiler. The average rated power for these CPPs is $370 \mathrm{MWe}$, ranging from single plants generating more than 1400 MWe down to a plant that generates only 1 MWe. U.S. operating coal plants are shown in Figure 2. ${ }^{19}$ 


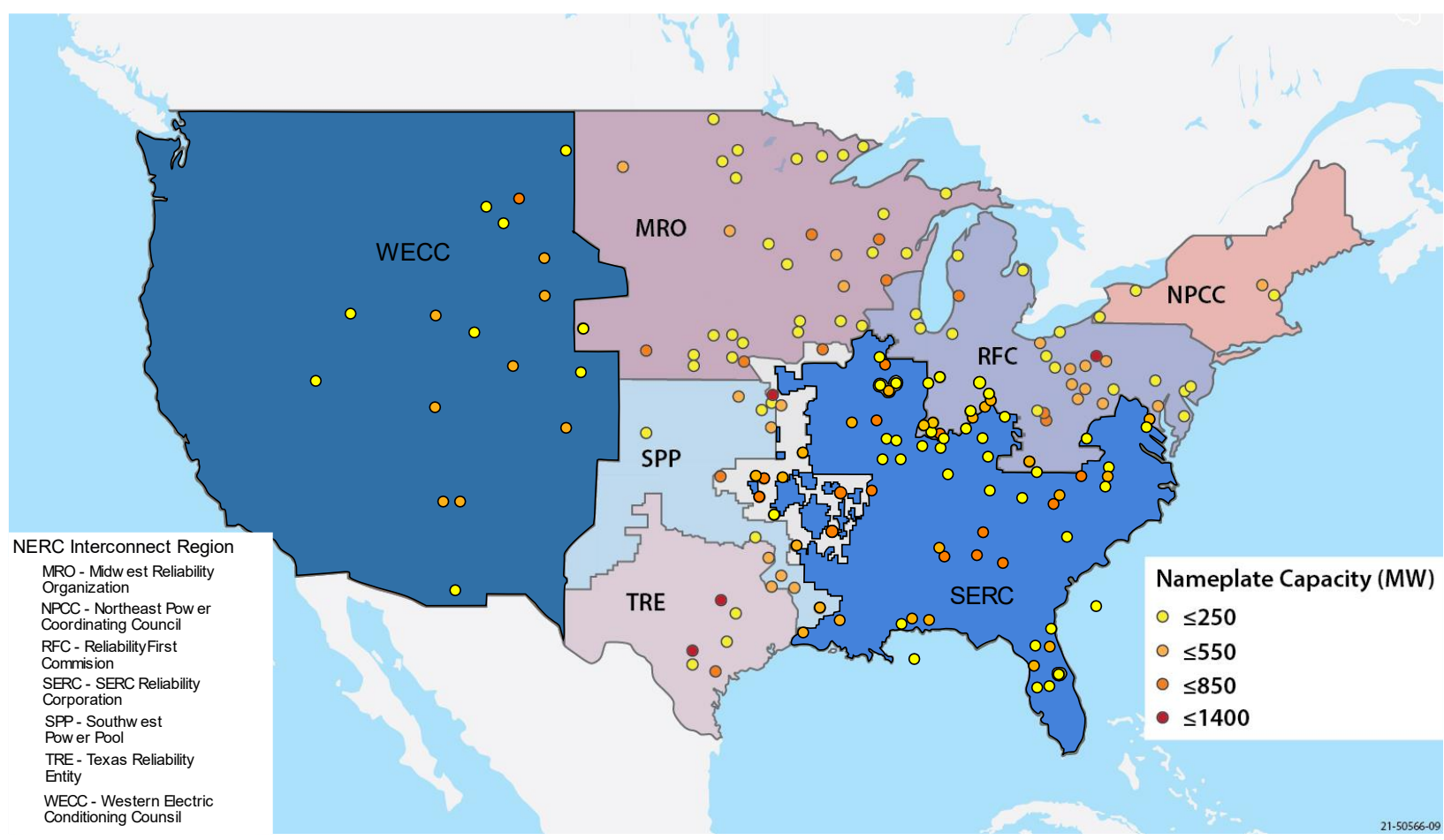

Figure 2: Currently operating coal plants in United States.

A simplified diagram is shown of a coal power plant is shown in Figure 3. Coal and ash handling, filtering, and washing equipment are operating challenges specific to CPPs. A CPP's burners and boiler system are also very different from the steam generators used in a NPP. The differences extend to the rest of the power-cycle equipment because of the components integral to the boiler at a coal plant. ${ }^{20}$ 


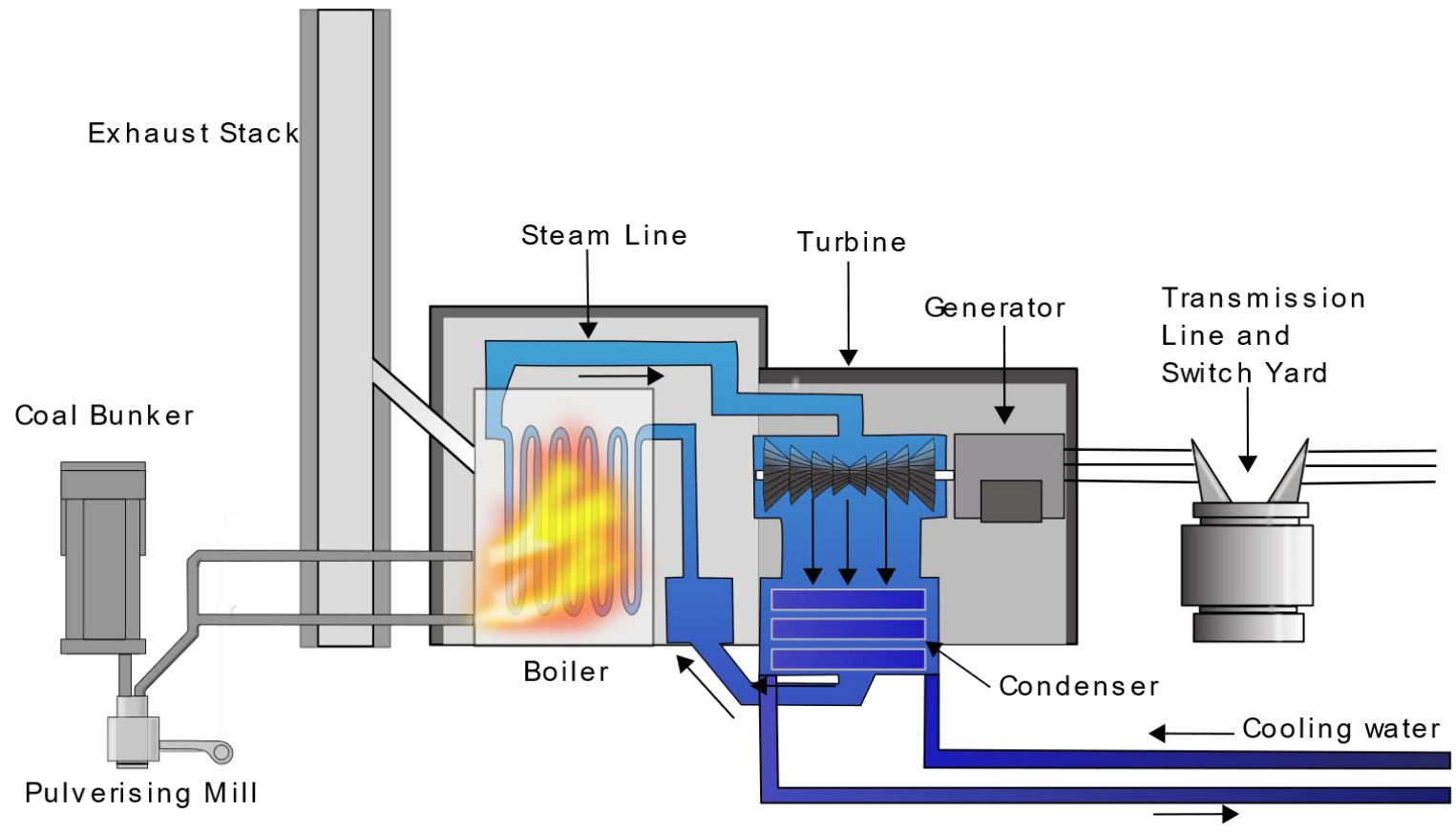

Figure 3: Simplified coal power plant

CPPs can be separated into categories based on the temperature and pressure of the steam generated in the boiler unit. In order of increasing efficiency, temperature, and pressure, CPPs include the following categories: subcritical ${ }^{21}$, ultra-supercritical ${ }^{23}$ power plants (Table 2). Improvements in materials available for CPPs have allowed for operations at increased temperature and pressure. A CPP's layout is also closely tied to the arrangement and flow paths of ash and filtered particulate waste materials. These and their component systems create complexity and take significant space in the power-plant systems.

Table 2. Coal operating conditions.

\begin{tabular}{|l|c|c|c|c|}
\hline Coal Power Plant & $\begin{array}{l}\text { Pressure } \\
(\mathrm{MPa})\end{array}$ & $\begin{array}{l}\text { Temperature } \\
\left({ }^{\circ} \mathrm{C}\right)\end{array}$ & Footprint (acres) & $\begin{array}{l}\text { Thermal Efficiency } \\
(\%)\end{array}$ \\
\hline Subcritical & 16.5 & 538 & \multirow{2}{*}{$\begin{array}{c}\text { 1-8 Acres/MW or } 19 \\
\text { acres }^{22}\end{array}$} & $37 \%$ \\
\cline { 1 - 3 } \cline { 5 - 5 } Supercritical & 22 & 600 & & $42 \%$ \\
\hline $\begin{array}{l}\text { Ultra- } \\
\text { supercritical }\end{array}$ & 32 & $610 .{ }^{23}$ & & $44 \%$ \\
\hline
\end{tabular}

These subcritical CPPs still operate at higher temperatures and pressures than the steam system of a PWR that turns the turbine and generator. PWRs operate at $8.3 \mathrm{MPa}$ and $292^{\circ} \mathrm{C}^{24}$ The steam and turbine systems are optimized differently for PWR and CPP conditions, making them much less compatible with each other. An advanced NPP operating at high temperatures could be as efficient as the CPP they replace, as shown in Table 1 and Table 2. This rise in efficiency does require using non-water coolants.

Unlike the steam-and-turbine systems, the electrical-generation equipment is much more similar between CPPs and NPPs. Power lines, transformers, and electrical-conditioning systems are largely the same. A NPP may need high-quality grid connections for house loads to support safety systems, but modern nuclear plants tend to depend less on offsite power. 
The combustion products created by the burning of coal and the many elements intrinsic to coal create a complex chemical environment inside the fired portion of the plant. Sulfur, chlorine, and halogen materials are especially problematic; these compounds would be equally problematic for any shared nuclear-system components. Combustion products are never featured in any part of a nuclear plant because they rely on nuclear fission for power.

\section{CONSIDERATIONS FOR REPLACING CPPs WITH NPPS}

The opportunity to replace a CPP with a NPP is becoming more attractive as replacing carbonproducing power plants is becoming a priority for utilities, regulators, and the general public. The new nuclear-reactor designs are well suited to replace CPPs and take advantage of existing power-plant site infrastructure. Beyond technical benefits, a new power plant would continue local-community benefits in terms of jobs, tax bases, and grid operation.

The replacement of a CPP with a NPP is a significant undertaking. Technology and regulation issues affect what is possible for a CPP-to-NPP transition. Additional non-technical factors to consider include the:

- Quality and value of the current connection to the grid (discussed in Section 3.3),

- Inherent value of the land (discussed in Section 3.3),

- Ability and desirability of the CPP being retired (discussed in Section 4.0),

- Condition and understanding of the site environmentally (discussed in Section 4.3),

- Suitability of the site to host a nuclear power plant (discussed in Section 4.4),

- Shared project engineering experience with coal and nuclear power (discussed in Section 4.5).

- Ownership expectations for the site (discussed in Section 4.5),

- Community support for the CPP to NPP transition (discussed in Section 4.6),

- Transport infrastructure from barge, rail lines and heavy haul roads.

An evaluation of all these factors is complex and dependent on the features of a particular CPP and the replacement NPP. The primary issues are discussed in the following sections and the case study.

\subsection{Coal Boiler and Nuclear Steam Generator}

CPPs and NPPs produce power in broadly similar ways, with both using a heat source to ultimately turn a turbine, power lines, transformers, and electrical-conditioning systems. However, there are significant differences in the mechanical systems, operating conditions, and regulation of these technologies.

One primary difference between a CPP and a NPP is the temperature and pressure regime at which the individual steam systems operate. CPPs use increased temperatures and pressures, compared to watercooled NPPs, to improve their thermal efficiency, as shown in Table 2. Advanced NPP achieve the same efficiency using higher temperatures and non-water coolants, at significantly reduced pressures as shown in Table 1. Current NPPs operate at saturated conditions, where steam and water exist together to drive the turbine. CPP overall steam pressures and temperatures have been steadily rising over time to improve thermal efficiency. A modern CPP can operate at ultra-supercritical conditions where the temperature and pressure are even higher than in supercritical CPPs, allowing further improvements in thermal efficiency. These ultra-supercritical boilers use modern steels that can operate in the boiler at high internal pressure. 
A CPP boiler also has multiple loops of water and steam tubes to provide preheating, superheating, and reheating in the power cycle. The boiler also must accommodate ash and combustion-product chemistry while remaining online. The $\mathrm{CPP}$ boiler is a complex and specialized tool. Comparisons to a large nuclear steam generator show that the NPP is a simpler, but equally high-performance system. The difference in piping layout is broadly shown in Figure 4, which shows the complex sequence of steamgenerating piping in a CPP, as compared to the relatively simple steam-generating system of NPPs.
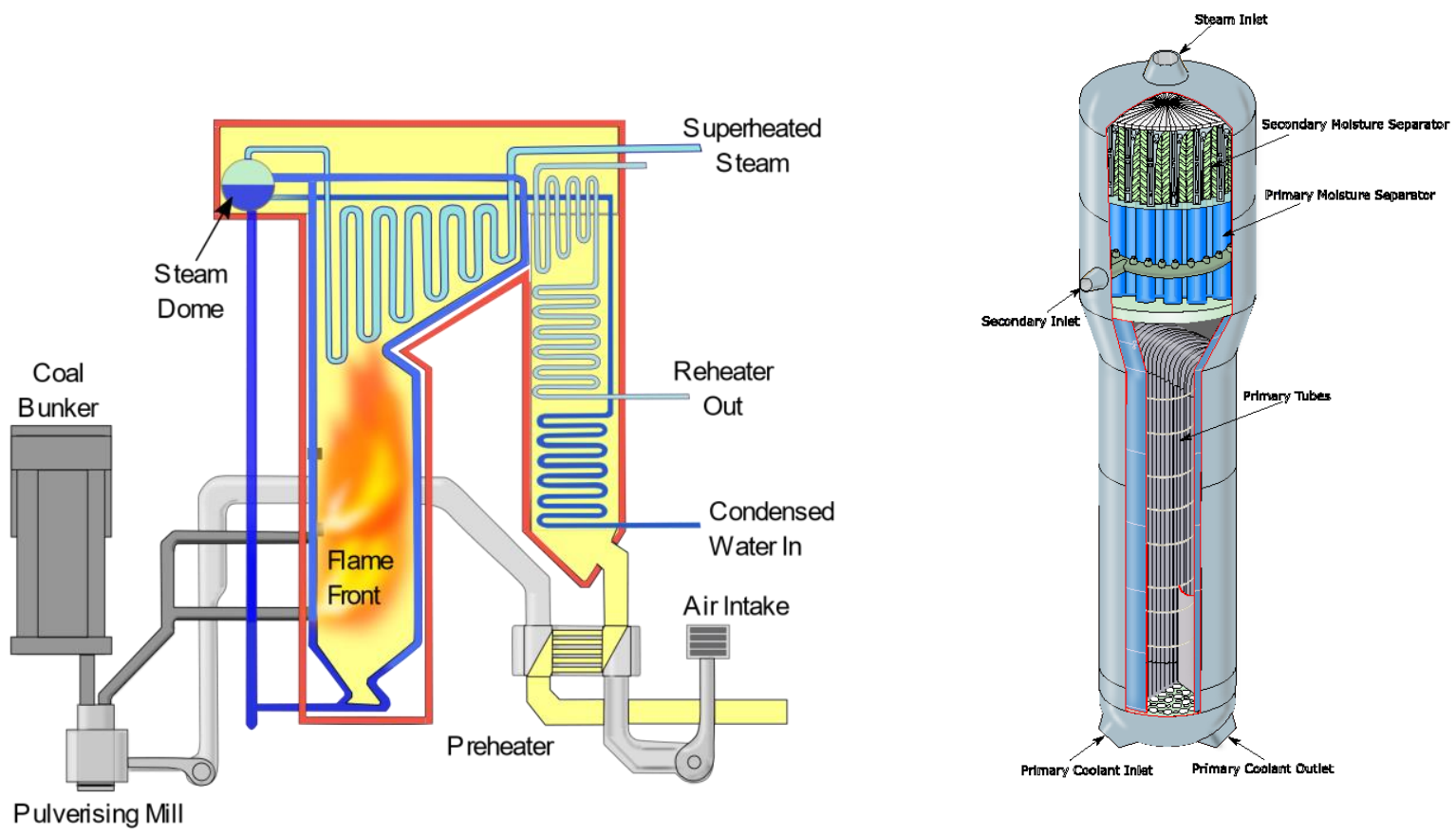

Figure 4. Coal boiler and LWR steam generator.

Because it uses hot gas as the reactor coolant, an HTGR is the reactor design most like a CPP. But even in comparing HTGRs and CPPs, significant differences exist between the optimized components. The steam generator at the vintage Fort St. Vrain HTGR reactor included many features of a CPP boiler, as shown in Figure 5. Of note is the multiple passes through the steam generator, something atypical of conventional nuclear reactors, but is in CPPs. Such differences imply that using an HTGR to replace combustion processes in a CPP boiler will require significant changes to the boiler design. Downstream system components are equally unlikely to be useful for the new NPP. 


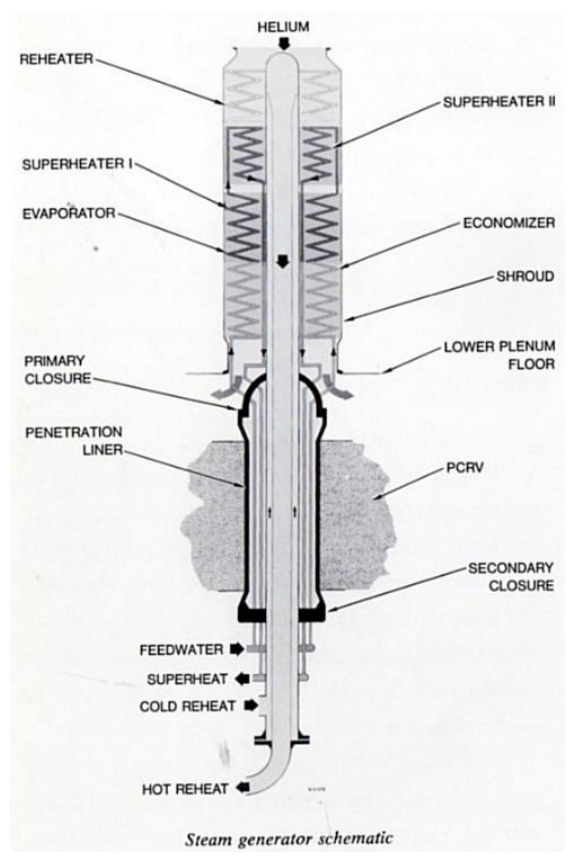

Figure 5. HTGR Fort St. Vrain HGTR steam-generator diagram.

\subsection{Coal and Nuclear Power Plants Technology}

Three options are often discussed when considering a coal to nuclear transition include: (1) reuse of the electrical switchyard and grid connection (2) direct connection and reuse of the steam system, and (3) indirect connection and reuse of the steam system. Maintaining any equipment from the retiring coal plant in order to potentially reduce the costs and total deployment time, requires compatibility between the coal and nuclear equipment. As covered in previous sections of this report, the equipment is not inherently similar to each other, and a purposeful attempt would be needed to combine the equipment into a practical, efficient system. Matching system requirements such as flow rates, temperatures, heat-transfer areas, and structural materials to the redesigned steam-generation system will be necessary to ensure that power from the nuclear reactor is efficiently converted into electricity on the grid. Beyond the efficient thermal-system design, NPP heat-transfer systems are tied to a safety analysis of the reactor as the response of the reactor to events is tied to the thermal system that removes heat from the reactor. The reactor is designed, analyzed, and licensed to be safe under all anticipated conditions. The nuclear system will entail additional safety requirements above the usual thermal requirements, and the new nuclear system will be required to be safe at all times. A particularly robust reactor design, with high thermal margins, will enable the new application, and detailed analyses will be necessary to ensure the system is safety and reliability of the final nuclear reactor system.

New and existing nuclear reactor technologies can match the rated power of the existing fleet of CPPs (Table 1). The use of multiple reactors within a NPP can help match the electrical output of the CPP in much the same way that a CPP uses multiple boilers. Different sizes of nuclear reactors can allow for a one-to-one replacement of boilers with reactors to more closely align with the characteristics of the CPP. A site can also undergo a full transition, in which the number of reactors is optimized to meet the power level for the site. The transitioned power plant output can also be set at a new, optimized level.

The differences between nuclear and coal will likely limit how much equipment can be retained. In many cases, transmission equipment and other site infrastructure can be reused. Some advanced reactors can produce temperatures high enough to support supercritical and ultra-supercritical steam, thus aligning 
with existing steam power generation systems. This may cause the turbine and generator systems to be retainable.

\subsubsection{Decommissioning CPPs: Preserving Transmission Connection}

The simplest method of replacing the CPP with a NPP is to decommission it and establish a NPP in its place. This would enable the site to be reused, without requiring the design of an interface to the CPP equipment presently on-site. Restarting from a brown-field condition allows for all the equipment to be new, as well as tailored to the approved and licensed nuclear system. A complete environmental cleanup of the CPP would be possible, eliminating any issues regarding trace heavy metals and actinides resulting from coal ash.

In the replacement scenario, the CPP power generation equipment is removed to simplify the NPP deployment. This option would be more appealing for small, older coal plants with limited or no value to the NPP.

The costs for demolition, salvage, asbestos abatement, and coal ash and filter-material management are all highly variable. ${ }^{25}$ Planning for decommissioning is a complex process that depends on the required end state ${ }^{26}$ Coal ash removal, material removed by filters at the site, and demolition represent a significant portion of these costs. The coal ash and filtered material also introduce even higher levels of uncertainty as the plan is developed due to groundwater contamination, needed mitigations, updated regulations, and other unknowns.

The final state of the CPP site prior to NPP deployment can affect costs. One benefit of repowering a site is that its useful features can be carried over as needed, to the new power plant. Foremost among the site's infrastructure and value are the grid switchyard and the grid connection. The value of the original CPP switchyard would reach millions of dollars. ${ }^{27}$ The cost/mile of transmission lines can exceed $\$ 3 \mathrm{M} / \mathrm{mile}$ and require multiple years of approval and construction. ${ }^{28,29}$

The CPP site will have a unique operating value. Having been permitted and operated, the site is better understood and characterized than undeveloped power plant sites. The power line rights of way, water- and air-use permits, and operating infrastructure all uniquely add to the site's value.

\subsubsection{Retaining Non-Power Block Infrastructure}

As with water supplies used for plant cooling and the electrical switchyard, reuse of infrastructure that supports power production will allow more value to be retained. The electrical switchyards and grid connections are potentially equivalent for both NPPs and a CPPs; thus, they are very valuable. A switchyard is the infrastructure most likely to be reused. A rough value of the substation would be in the tens of millions of dollars. ${ }^{30}$ The plant's existing switchyard would require an engineering evaluation as well as potential upgrade investments in order to be used. To support the NPP, it may be necessary to ensure that the design basis and maintenance status are at the expected levels.

A plant's service water and ultimate heat sink may also represent significant value. A CPP with an effective service-water supply would contribute to deployment if the permitting is carried over to the NPP. A reusable ultimate heat sink is potentially one of the most-valuable features of a CPP. As with service water, reuse of the ultimate heat sink may require reapproval and permitting. Grandfathered systems may be unusable going forward due to changes in regulations and expectations and transferring the plant to an air-cooled system or best-available technology may be required. Security, firefighting, and medical services may also transfer from the existing CPP to the new NPP.

\subsubsection{Cost and Value of the Decommissioned Coal Plant}

The cost of constructing a modern gigawatt CPP is in the \$2-3B range for the full plant. ${ }^{31}$ The value remaining in an existing CPP at any given moment is complicated and the value continues to changes. ${ }^{32,33}$ The reduced value, the potential need for continued investment, and the economic pressures are forcing 
the closure of an increasing number of CPPs. ${ }^{34}$ The value remaining in these power plants is complicated by the planned depreciation, potential rescheduled depreciation, and securitization of the plant debt. ${ }^{35}$

The cost of an example $610 \mathrm{MWe}$ combined cycle CPP is givens as \$2.8B in 2009 dollars as shown in Table 3. Most of these components would not typically be recycled. Use of a heat sink to separate nuclear and coal systems could potentially allow roughly $\$ 150 \mathrm{M}$ of equipment to be reused. All carriedover equipment would need to be evaluated, an upgrade maintenance plan developed, and investments, procured. The reduced value of the whole plant in today's market, combined with the operating wear, nuclear pedigree, and need for maintenance, makes reuse of this power-producing equipment to be of seemingly minimal value.

Table 3. Reduced costs for 610 MWe combined cycle CPP (2009 dollars).$^{27}$

\begin{tabular}{|l|r|r|}
\hline Unit Size, MW Net & \multicolumn{1}{|c|}{610} & \multicolumn{1}{c|}{ NPP Reuse } \\
\hline Coal and Sorbent Handling & $\$ 36,007,000$ & \multicolumn{1}{c|}{ No } \\
\hline Coal, Sorbent Prep, and Feed & $\$ 159,390,000$ & No \\
\hline Misc. Balance of Plant Systems & $\$ 48,779,000$ & \multicolumn{1}{c|}{ No } \\
\hline Subtotal Gasifier and Accessories & $\$ 614,540,000$ & \multicolumn{1}{c|}{ No } \\
\hline Gas Cleanup and Piping & $\$ 145,163,000$ & No \\
\hline \multicolumn{1}{|c|}{ Subtotal Combustion Turbine and Accessories } & $\$ 127,167,000$ & Analysis Required \\
\hline Subtotal Heat Recovery Steam Generators, Ducting, & $\$ 68,068,000$ & No \\
\hline and Stack & & Analysis Required \\
\hline Direct Project Costs & $\mathbf{\$ 1 , 5 1 5 , 8 3 8 , 0 0 0}$ & \\
\hline Total Project Costs Including Indirect Costs & $\mathbf{\$ 2 0 0 , 4 9 1 , 0 0 0}$ & \\
\hline
\end{tabular}

CPP decommissioning costs are relatively high compared to those for other conventional power units, averaging over $\$ 117,000 / \mathrm{MWe}$, and depending on many factors, such as the ultimate plan for the site. Returning the site to a green field condition costs more than a site already in redevelopment condition. High intrinsic land values near growing cities can impact what is desired for the site in the future. Understanding the necessary decommissioning costs will depend on the site's future use.

The value of the retired CPP can remain considerable, including its real-estate value, which may have increased substantially since the plant was built. The inherent value of the existing plant, grid connection, site analysis, and cost of decommissioning and demolition (D\&D) may be exceeded by the potential value in developing the site for new purposes. ${ }^{36}$ This option would enable decommissioning costs to be shifted in the sale, if necessary. The average cost of decommissioning a coal plant is estimated as $\$ 117,000 / \mathrm{MWe} .^{25}$ This estimation is potentially low since extra cleanup may be required to meet the nuclear requirements for a an environmentally clean location.

\subsubsection{Retaining Power-Block Infrastructure: Reusing Steam Supply}

The CPP's steam-handling system and turbine are expensive components. Retaining these systems could potentially transfer this value to the new NPP. If the NPP can produce steam at the required pressure and temperature, the turbine and steam system may be reusable. For efficient operation the 
CPP/NPP layout may require rearrangement. The design basis and maintenance status would need to be established in accordance with nuclear standards to support site and reactor licensing.

A connection between the new nuclear reactor and the power-producing system must be established. Direct connection via a steam generator or boiler would require significant analysis and, in all likelihood changes and updates to the hardware. The design of a heat storage system for that connecting nuclear and coal systems should be considered in order to enable plant operation, thermal efficiency, and licensing. Use of heat storage could provide beneficial in matching grid demand to the plant's power output and allowing for direct-heat applications such as hydrogen, ammonia, and synthetic liquid-fuels production and desalination. A high-temperature reactor and heat storage system could enable reuse of the existing high-pressure secondary plant. Separation of nuclear- and coal-related equipment may also help in terms of licensing and design options.

The replacement nuclear system would require removal of the power-block coal-handling, ashmanagement, and filtering systems. Given that these systems are physically large and integrated into the plant, this is a significant task, involving several interdependencies with other systems and deployment of the new plant. Removal of unnecessary systems will free up space at on the site so new equipment can be deployed. Scheduling removal and replacement of these systems would be more complex for this option.

Retention of a boiler or primary-heat-source equipment from the CPP when transitioning to nuclear appears highly unlikely. Even for cases in which a high-temperature nuclear reactor could drive an existing coal boiler steam generation system, the analysis would be specialized and unique to the reactor and steam supply system.

\subsubsection{Repowering Options: Indirect Connection to Steam Supply}

One way to reduce the demand arising from reconfiguring existing steam systems at a CPP is to disconnect the NPP's heat generation from the CPP's steam system. A large heat-storage unit could potentially enable heat from a NPP to be effectively delivered to the existing CPP steam system. This necessitates a high-temperature storage system similar to, but potentially larger and higher in temperature than, a solar heat-collection system. ${ }^{37}$ Disconnecting heat production from electrical generation can allow for the separate design of a connection between the two systems. Such a disconnect could also allow for a simpler licensing analysis for the nuclear reactor, which could simplify licensing. A heat storage system could be used to separate the new safety- and nuclear-related systems from the legacy steam system of the pre-existing CPP. The stored heat can also be pulled from the heat reserve as needed, allowing flexibility in meeting power demand. A nuclear system (i.e., the Natrium reactor) that utilize heat storage is being developed by TerraPower. ${ }^{38}$ The heat storage system does introduce additional expense and complexity to the repowering, but the benefits to licensing and system design could outweigh the added complexity.

\subsubsection{Non-Power Infrastructure Retained}

Retaining buildings and equipment that service the site should reduce certain developmental costs. Retained warehouses, office buildings, commercial water, sewer, rail lines, heavy haul roads and electrical services could save deployment costs. This approach allows value to be retained while also speeding up the deployment timeline. Retaining these types of infrastructure would save on costs and simplify the development of support infrastructure. This would provide additional benefits in terms of reducing the number of site changes required in regard to footprint and use.

Analyses and information created to support CPP operation also benefit the NPP. Understanding the local environment will inform the characterization of the site for nuclear use. Unneeded Equipment Removal

Regardless of the scenario, the coal plant will include some unneeded equipment, such as that pertaining to delivery and storage of coal supplies, coal transfer systems, and coal storage. Similarly, the ash-handling and conditioning systems can be removed. These radioactive elements would interfere with 
radiation control and pose a disposal risk to the new NPP. Any radioactive material or contaminants left at the plant could cause a very high-cost disposal issue under NRC regulations. More typical remediation of industrial chemical contamination of a site is also of particular importance, since any nuclear materialeven that produced by coal ash-could represent a nuclear waste liability.

\section{SITING CONSIDERATIONS}

The major difference between siting a NPP and a CPP is that NPPs regulated by the U.S. NRC. NRC was created from the U.S. Atomic Energy Commission in 1978 and it oversees and licenses all commercial nuclear applications. NRC oversees all aspects of NPP operation and combines multiple functions stemming from various CPP-regulating federal agencies. The intent of NRC regulations is to ensure public safety and the safe operation of NPPs. NRC will directly regulate any aspects of the NPP that could potentially affect its safety basis. Siting for current-generation NPPs is well established and has been encoded into regulation.

Although the newer generation of NPPs that feature advanced technologies could be regulated under the current standards, NRC is working to optimize the licensing of advanced reactors. Vendors of advanced reactor also contribute new analyses, as necessary, to gain approval for unique operating features.

NRC's goal of ensuring safe operation under all operating conditions may require a more detailed analysis than that required for a CPP. Increased detail, environmental, quality requirements, and completeness of the analysis should be expected in applications for an NRC operating license.

\subsection{Changing Regulator}

Federal regulation of CPPs is primarily performed by the U.S. Environmental Protection Agency, which seeks to ensure public safety related to air, water, and environmental quality. To operate a commercial NPP, a U.S. company must have an approved NRC operating license. This operating license represents the final step in the sequence of approvals initiated by an application to operate a NPP. The site of the NPP can be approved with an assumed-bounded NPP design. This site review results in an early site permit (ESP) which can be established and held until a specific reactor design can be deployed. The choice of licensing approach is complicated and dependent on different project sequencing and requirements. ${ }^{39}$

\subsection{NRC Review Information}

$\mathrm{NRC}$ is the lead federal agency for conducting nuclear reactor license reviews. An environmental assessment (EA), developed and supplied to NRC by the licensee, is used by NRC to perform a National Environmental Policy Act of 1969 (NEPA) review (see 10 CFR 51). The NEPA analysis process requires that all agencies of the Federal government prepare a detailed environmental evaluation on any proposed major federal action, (e.g., issuing a reactor operating license) that may significantly affect the quality of the human environment. A principal objective of NEPA is for these federal agencies to consider the environmental impacts of their actions. NRC also requires that alternative sites be considered in the NRC's decision-making process. The NEPA analysis is intended to evaluate any effects on the environment, as well as the interactions with other human activities that were evaluated as part of the EA.

CPPs entail specific concerns regarding air quality, ash handling, thermal discharges, fuel supply logistics, and contamination. Changing to a NPP eliminates any issues with ash and coal handling. ${ }^{40}$ There are effectively no air emissions at a NPP beyond trace amounts of activated gases released from the primary coolant system. ${ }^{41}$

\subsection{Environmental Conditions Requirements}


Other specific effects caused by the new NPP in regard to the environment and local communities must be evaluated, including effects on wildlife species and clean water and air, as well as cultural, meteorological, flooding, seismic, and volcanic features. Though these should be essentially the same issues tracked and managed for CPPs, they can potentially be more involved for NPPs. NRC's documentation requirements may differ from those of the EPA, especially as they relate to the safety evaluation and reactor performance. Collecting data and documenting all issues are significant aspects of creating the EA and overall license application ${ }^{42}$

Converting a coal site to nuclear power has a potentially unique environmental concern. Coal naturally contains small amounts of radioactive material directly from uranium and its decay products. ${ }^{43}$ The radioactive material can be detected by the sensitive monitoring systems of a NPP. Any radioactive material at the NPP is regulated by NRC and would need to be treated as a radioactive-waste stream after an NRC license is issued. This would potentially make disposal of any remaining coal combustion residuals (CCR) much more expensive. ${ }^{44}$

In a draft white paper, NRC reviewed previous EA for critical environmental topics. ${ }^{45}$ Early communication and attention are considered beneficial for NRC and the license applicant alike. The following items were identified by NRC as being important and potentially causing review delays:

- Socioeconomic characteristics of the community

- Aquatic or terrestrial ecology studies that have been performed (if any)

- Federally listed species and critical habitats present, and potential impacts on those species and habitats

- Potential impacts on essential fish habitats, including prey of federally managed species

- Historic properties and other cultural resources

- The fuel cycle and its impacts as related to the reactor design including the management of spent nuclear fuel

- Environmental impacts from the transportation of fuels and wastes

- Design-specific information needed for the environmental review

- Non-radiological waste management

- Postulated accidents and severe accident mitigation design alternatives.

This review information represents a full evaluation of the impact of the NPP deployment.

\subsection{Siting}

NRC Regulatory Guide 4.7 provides guidance on siting properties, including several desirable properties for a site, such as those listed below. Some modern reactors with unique designs may not be affected by these siting properties, such as having a reactor without safety-related water requirements. A plant that does not use external water to keep the plant safe would be much less dependent on the site's water supplies. Regulatory Guide 4.7's desirable properties involve injunctions to:

- Avoid areas of surface-water flooding/ponding

- Maximize the proximity to suitable sources of cooling water

- Minimize disturbance of the critical habitat of protected species

- Avoid areas with cultural, economic, or historic resources

- Minimize potential adverse interactions with existing programs 
- Minimize or account for man-made hazards

- Ensure appropriate security controls are available.

In general, an existing CPP will have those features expected of a NPP. Evaluation of the NPP will center on potential safety issues, so certain factors (e.g., man-made hazards) may be evaluated more closely.

\subsubsection{Ultimate Heat Sink}

Large CPPs require a way to remove heat from burning coal that has not been converted into electricity to operate continuously. This heat is typically transferred to a water-based system. This can be within cooling towers or a large body of water. NPP shares a similar need to transfer extra heat from the plant. An existing workable heat sink is essentially ensured by the site's previous usage as a CPP. Because ultimate heat sinks are potentially very expensive to establish, they add value to the CPP site value other locations may be lacking.

A water-based ultimate heat sink can use huge volumes of water to reject heat from a NPP. ${ }^{46}$ Usage of water from rivers, lakes, and oceans in once-through loops has been replaced with an expectation that best-possible technology be used. ${ }^{47}$ This can take different forms given the range of reactor technology that can be deployed. Many modern, especially smaller reactor designs are air cooled and do not require large amounts of water to operate. Selecting a reactor design most suited to a site and the potential ultimate heat sink is one of the critical steps in deploying a NPP. Not using water for the ultimate heat sink also makes procurement of needed water rights much easier and enables community acceptance.

\subsubsection{Connecting to the Grid}

A major potential benefit of siting a NPP at a recycled CPP site is that the equipment for transferring the produced power to the commercial grid, and from the grid to the NPP (for house loads), is already in place. If the NPP's power levels match those of the CPP, this should allow for minimal investment in the local grid. Adding new grid connections or upgrading existing grid access can require strategic investments from the grid and NPP operators alike. Local grid access can be complicated if significant changes are required. Having the cooperation of the local grid operator and electrical-power companies will reduce the time and cost of installing new NPP generation. One potential benefit of converting to natural gas is that it can allow time for agreements and upgrades to be made before the NPP goes online.

A NPP may also require highly reliable power during and after an accident to be supplied by the electrical grid. Creating the needed reliability can require upgrades to plant switchyards that demand cost and time. Selecting a NPP design that matches the capability of the local electrical grid can provide project benefits. ${ }^{48}$ Using an established grid configuration will simplify North American Electric Reliability Corporation compliance, preventing changes and upgrades from being required in order to maintain grid stability.

\subsubsection{Transport Infrastructure}

CPPs also require the capability to receive a large volume of coal at the CPP site. Usually this is in the form of high-capacity rail or barge transportation. A co-located CPP and mines may only have robust local transport. Ongoing CPP operations also require that effective heavy-load roads are available. This capacity is useful for the buildout of a NPP and on-going operation. SMRs and smaller reactors are designed to be transported with heavyweight trailers used for large and heavy objects. Transport of fresh fuel to the NPP can be accommodated by road transport. These logistical benefits would not necessarily be available at typical undeveloped sites. Industrial transportation would also allow coproducts from integrated energy systems (IESs), like hydrogen and ammonia, to be moved away from the site to market.

\subsubsection{Timeline}

Advanced NPPs are being designed with shorter deployment timelines than those for previous reactors. Building standard units in factories and using smaller, modular reactors reduces required 
development time. Characterizing the site for a NPP license application and the NRC review can take years. Two conventional NPP plants, Vogtle Units 3 and 4, received their combined construction and operating license in 2012. ${ }^{49}$ These plants are $92 \%$ complete as of April 2021. The Barakah 1, a large Korean advanced PWR APR1400 reactor design deployed in the United Arab Emirates, started construction in July 2012 and began operation in March 2021. The Barakah 1 is part of a four-unit NPP. ${ }^{50}$

NuScale, using factory-built SMR reactors, proposes a 36-month construction time from approval to construct their NPP design. The NuScale reactor's 36-months construction time is a projection. ${ }^{51}$ The rapid deployment is intended to reduce project risk and costs. These timeframes are aligned with natural gas repowering projects. Combining NPP deployment and an integrated CPP decommissioning, and demolition (D\&D) project would add overall complexity.

\subsection{Other Considerations}

Some unique conditions apply to a coal-to-nuclear transition. These conditions are not directly regulatory or technical but can support or hinder a transition project.

\subsubsection{Plant Ownership and Government Support}

A CPP's having a single owner, or at least a lead owner (as opposed to multiple equal-share owners), simplifies the management and decision-making for a coal-to-nuclear transition. Multiple owners would naturally have different goals for a CPP. This would tend to complicate project planning, funding, and ownership of the NPP.

The potential cultural change from CPP to NPP operation at all levels of the organization could benefit or hinder a project. The lead owner's having NPP and CPP experience would also be helpful, as would having staff directly available to inform both coal and nuclear issues. Having a nuclear operating company to support the project or potentially plan NPP operations would also be beneficial.

Government funding to support CPP D\&D, job retraining, site characterization, and licensing would all be helpful to the coal-to-nuclear transition. Flexibility in how government support helps the local community would be beneficial. Cooperation between local, state, federal and corporate entities will improve the chance of project success.

\subsubsection{Repower and Renewables}

The large area required for a CPP and its coal-handling equipment provides an intrinsic opportunity to use the space. Because an SMR would take up relatively little space once completed, the unused area could be committed to additional energy generation. ${ }^{22}$ Adding a collocated renewable-energy system can improve a company's zero-carbon portfolio. Having an SMR capable of changing power output to meet grid requirements with a local renewable resource could provide rapid flexible response to power demands. Adding energy or heat storage collocated to the SMR would further increase generation options. Deploying the combined nuclear/renewable system with incremental deployment of renewables would also allow optimization of the site power production.

\subsubsection{Integrated Energy Systems}

A NPP transition can be aimed specifically at electrical production, with the NPP producing power as its only product and competing directly in the electrical market. This application is a direct reuse of the site, and success would depend heavily on the cost of electricity generated and benefits to the total electrical supply. Most new NPPs can provide power as required to the grid, ensuring consistent performance. This capability to change power as required allows additional operating options.

Taking advantage of the controlled NPP power and the additional site area could also be used for IES production, wherein the plant supports energy activities such as hydrogen production, desalination, or industrial heating in addition to electricity production. ${ }^{52}$ The use of nuclear heat to produce products other 
than electricity provides an opportunity to separate plant operation from grid demands and volatile electricity prices. The incorporation of IES systems can benefit power-plant economics and support localcommunity economic options.

Additional industrial applications could be directly supplied by nuclear power and be built in conjunction with the NPP. Local industries could take local nuclear power as electricity or heat from the NPP without needing distant electrical-transmission or heat-transport costs. The industrial applications can potentially be ramped back, allowing the NPP to contribute additional power to the grid when required. This creates the reverse market engagement, where industry is primarily served and the grid supplied as desired, compared to more typical IES applications.

\subsection{Workforce and Community-Related Topics}

Community and regional benefits are very complex and depend on local conditions; for this reason, a complete evaluation is beyond the scope of this report. However, this section highlights a few high-level considerations. The closure of a CPP without replacement creates significant changes to a local community. Stable, good-paying jobs disappear, which removes income from the community, reduces the tax base, and affects real-estate values. The loss of the corporate tax base greatly reduces the tax base for a community. The smaller, poorer, and more-isolated the community, the greater the affect. ${ }^{53,54} \mathrm{~A}$ coal-tonuclear transition and resultant NPP would benefit from community support, such as through workforce retention. The NPP would also support the local community economically by maintaining the local tax base. ${ }^{55}$

A new NPP would play a similar role in the community as the retired CPP when it operates. The reduction in air emissions and elimination of coal transport should improve the local environment. These improvements should be welcomed by residents.

The crew that operated the CPP would be able to transition to NPP jobs, and additional jobs would be created for security and warehousing. Additional higher-paying jobs to provide operating staff, maintenance, and engineering for the plant would be created. ${ }^{56,57}$ Retraining of staff could provide opportunities for some direct job upgrades and transitions. Nevertheless, advanced nuclear reactors will tend to have smaller crews than currently operating NPPs.

The transition from coal to nuclear would also create jobs for decommissioning the CPP and building the NPP. Several thousand contractors can be involved in building a NPP. The benefit of the D\&D and new build can make up for closure of the CPP in the local community and could provide employment during the period between CPP shutdown and NPP startup. Ongoing NPP refueling outages will provide the same benefits seen in CPP maintenance outages. ${ }^{58}$ Given the complexity of retiring a CPP for the operating company, plans for the local community can be expected to also be complex and would require significant and ongoing community interaction..$^{59}$

As an example of the potential economic benefits of a NPP, the deployment of a SMR, in particular, has been studied as part of the Utah Associated Municipal Power Systems carbon free power project, which is projected to deploy and operate a six-commercial-unit NuScale SMR on the Idaho National Laboratory Site. ${ }^{60}$ The economic benefits for both the construction and operation of the SMR were evaluated for the Idaho Policy Institute in 2019. ${ }^{61}$ NuScale has also evaluated the benefits of replacing a CPP with a NuScale SMR. ${ }^{62}$

Construction of the SMR, initially planned for 12 reactors on the INL Site, was estimated to create 2,000 direct jobs that translate into 13,400 job years. The construction would occur over approximately 4 years. The construction activities would support another 1,300 jobs in the community. The labor cost for this work was evaluated at $\$ 640$ million. Taxes related to construction locally would increase by $\$ 37$ million, and federal tax revenue would increase by $\$ 140$ million. The project would create 360 plant operating jobs and another 670 long-term jobs in the region. 
The operation of the plant would create 360 permanent jobs on the site, 270 of them as direct plant staff, ${ }^{61,62}$ and an additional 670 regional jobs. The NuScale plant would be licensed initially for 60 years. ${ }^{63}$ These jobs are the approximate equivalent to $\$ 48$ million in local income. Local taxes would increase by nearly $\$ 3$ million/year and almost $\$ 11$ million federally.

Other SMR designs, particularly LWRs, should produce similar economic results. A small modern LWR, for example, has approximately 75 staff for normal operation of each $300 \mathrm{MWe}$ unit. ${ }^{64}$ Advanced high-temperature reactors could be considered for unique applications like hydrogen production and enabling chemical reactions less suited to lower-temperature LWR reactors.

\section{CASE STUDY: COLSTRIP CPP}

The Colstrip CPP in south central Montana possesses intrinsic value thanks to the grid connection, ultimate heat sink and local community. The town of Colstrip is anticipating changes in the near future because the operating CPP maybe shut down. The plant at Colstrip is used as a high-level example of a CPP that could transition to a NPP. Coal-to-nuclear transition issues, particularly community affects, are noted.

The small town of Colstrip started as a company town to support a dragline coal mine that fed railroad locomotives, and the town is strongly focused on the local coal mine and collocated CPP (Figure 6). The supply of coal to railroads stopped in the late 1950s, leading to a mine shutdown until the 1970s. The surrounding area is predominately used for agriculture. Returning the plant to agricultural use would not concentrate economic resources, as does energy production. The land has no strong competing use to drive up the value as might be the case if it were it adjacent to a large city.

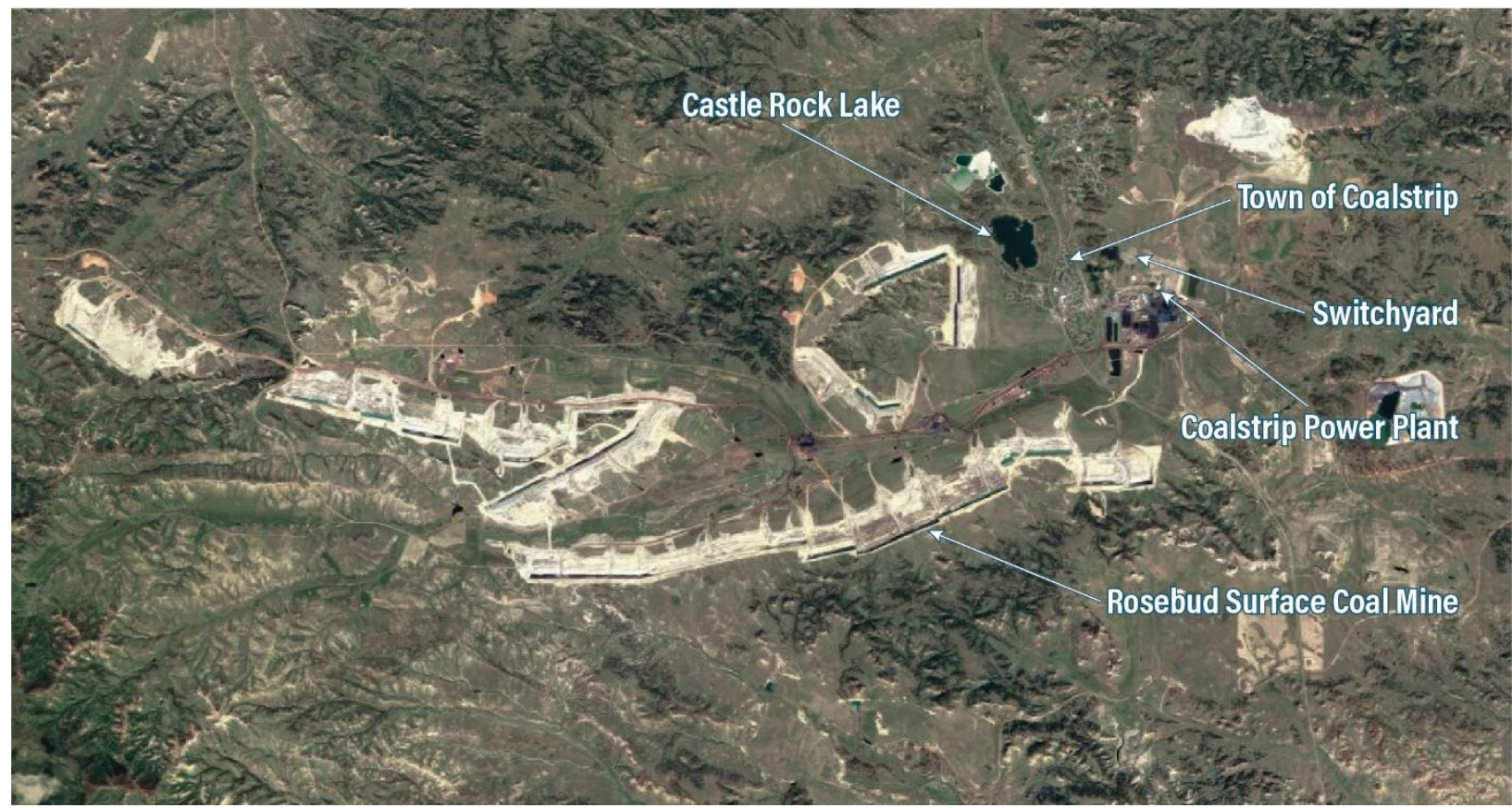

Figure 6. Colstrip Power Plant area, showing large area of the CPP system.

The mine was reopened in the $1968^{65}$ to support two local 358 MWe CPPs. Water for the plant's cooling is supplied from the Yellowstone River, 30 miles away, and locally held in at a lake adjacent to town. In the 1980s, two more CPPs of 778 MWe were built. ${ }^{66}$ The town population peaked around 13,000 in the 1980s as the plants were being completed. The town has around 2200 people now. In 2020, the two original smaller CPPs were shut down 30 months earlier than planned, indicating the power was not required. The plants have changed ownership through the years. 
Plant shutdown greatly impact the community. When the oldest of the plants was shut down, about 100 of the 330 plant staff were laid off. ${ }^{67}$ The plant had an annual payroll of $\$ 40 \mathrm{M} .{ }^{68}$ The reduction in the amount of coal supplied would have also placed pressure on the approximately 600 jobs at the adjacent coal mine owned by Westmoreland Rosebud Mining, LLC. ${ }^{69}$ Reductions in the volume of coal being mined decreases the royalties and taxes from the coal mine. Upon shutdown of the remaining CPP, all power-production jobs would become unnecessary. The local Native American communities would also be directly affected due to loss of employment. This could reduce the county revenue by $\sim 10 \%$. The shutdown of the plants also directly reduces the value of the plant, which reduces taxes based on value by $\sim 20 \% .^{70}$

Work to decommission and clean up the site is estimated to last between 18 and 30 months, ${ }^{71}$ but with a reduced staff, estimated at 200 people. ${ }^{69}$ Given the severe consequences on the local community created by closing the plant, corporate, state, and federal aid has been considered to support the community. ${ }^{72,73}$ The state of Montana community-support fund would support workforce development, economic transition, and continued assistance to maintain the plant site, but these funds cannot support the entire community indefinitely. The potential shutdown of the remaining CPP in Colstrip places the community under stress and creates uncertainty. ${ }^{69,70}$

\subsection{Alternate Use of the Colstrip Area}

An option to replace the CPP and retain the value of the Colstrip site is to consider a transition to a NPP. The Colstrip site is physically large and supports large amounts of power generation. It also has a community supportive of power production, a state government interested in reinvesting in the site, a useful water supply for an ultimate heat sink, and owners interested in new uses for the site. A detailed plan for repowering the site is the starting point for the transition. The long history of operation, decommissioned plants, and multiple owners all indicate that an understanding of the reuse, demolition, cleanup and construction tasks is needed. ${ }^{31,71,72}$

The value of having a well-developed grid-connection and power-transmitting capability would be retained by a NPP. This would allow the site to be repowered with one or more SMRs, approximating power rating of the CPP. The Colstrip mine and power plant occupy more than 40 square miles. ${ }^{74} \mathrm{An}$ average typical NPP would have only a 1.3 square mile footprint per $1000 \mathrm{MWe} .{ }^{74} \mathrm{SMR}$ designs claim to use even smaller plots of land. This provides flexibility in siting the SMR to minimize deployment costs. The large area allows for more-flexible siting and the option to further develop the site with an integrated energy system or renewable energy resources.

The two power plants that make up the Colstrip CPP produce $778 \mathrm{MWe}$ each, a power level that could be matched with multiple reactors listed in Table 1 . The high inherent safety of advanced reactors - and the large area around the Colstrip plant - may allow a modern NPP to be sited near the collocated Colstrip town.

There are six owners of the Colstrip CPP. ${ }^{70}$ The owners seek to close the plant to reduce carbon emissions. Talen Energy operates both NPPs and CPPs, making it a favorable candidate to transition from coal to nuclear. The state of Montana is looking into a study of a nuclear transition at the site and has funds set aside for community support. ${ }^{73}$

A recent study shows that an SMR approximates the staff requirements of the existing CPP. Although some specialized staff, such as trained technical nuclear staff and senior plant managers, would likely not come from the staff of the $\mathrm{CPP}^{75,76}$ much of the existing staff will be able to be retrained to work at a NPP. This offers the potential to support local families and the community over the long term. Complete NRC licensee training for the operating staff could take 18-24 months. ${ }^{75,76}$ The jobs that resulted from the Rosebud coal mine would still likely be lost given that the nuclear plant will not need coal.

\subsection{Deploying an SMR}


A high-level review of an example NPP is presented below, including some of the siting considerations particular to a specific plant. The example plant history and community are described as related to retiring in the $\mathrm{CPP}$.

\subsubsection{Colstrip Plant Repowering}

A coal-to-nuclear transition would require multiple planning steps and actions to justify the project. The Colstrip site would need characterization to support NPP siting, including meteorology, cultural, seismic, flooding, volcanic, and environmental evaluations. The seismic evaluation could be a long and expensive evaluation because no other nuclear plants have operated in that area. Other factors from Section 4 that impact nuclear siting appear to be adequate for nuclear siting.

The cost of D\&D of the existing CPP would need to be estimated. Managing regulated materials including asbestos, polychlorinated biphenyls, and mercury-is typical in other CPP D\&Ds. Issues to be managed below grade arising from any releases need to be evaluated. A reuse, salvage, and demolition plan, including the two shutdown boilers, is also needed. These evaluations of the site condition would allow a better estimate of the total work needed and a total cost estimate. Coal-decommissioning costs have a significant range, $\$ 117,000-466,000 / \mathrm{MWe}$ estimated, in 2016, because of unknowns affecting costs and unique situations for each plant. ${ }^{25,78}$

Figure 7 shows the Colstrip area with additional features, particularly the electrical switch yard and the nearness of the town of Colstrip and the Rosebud mine.

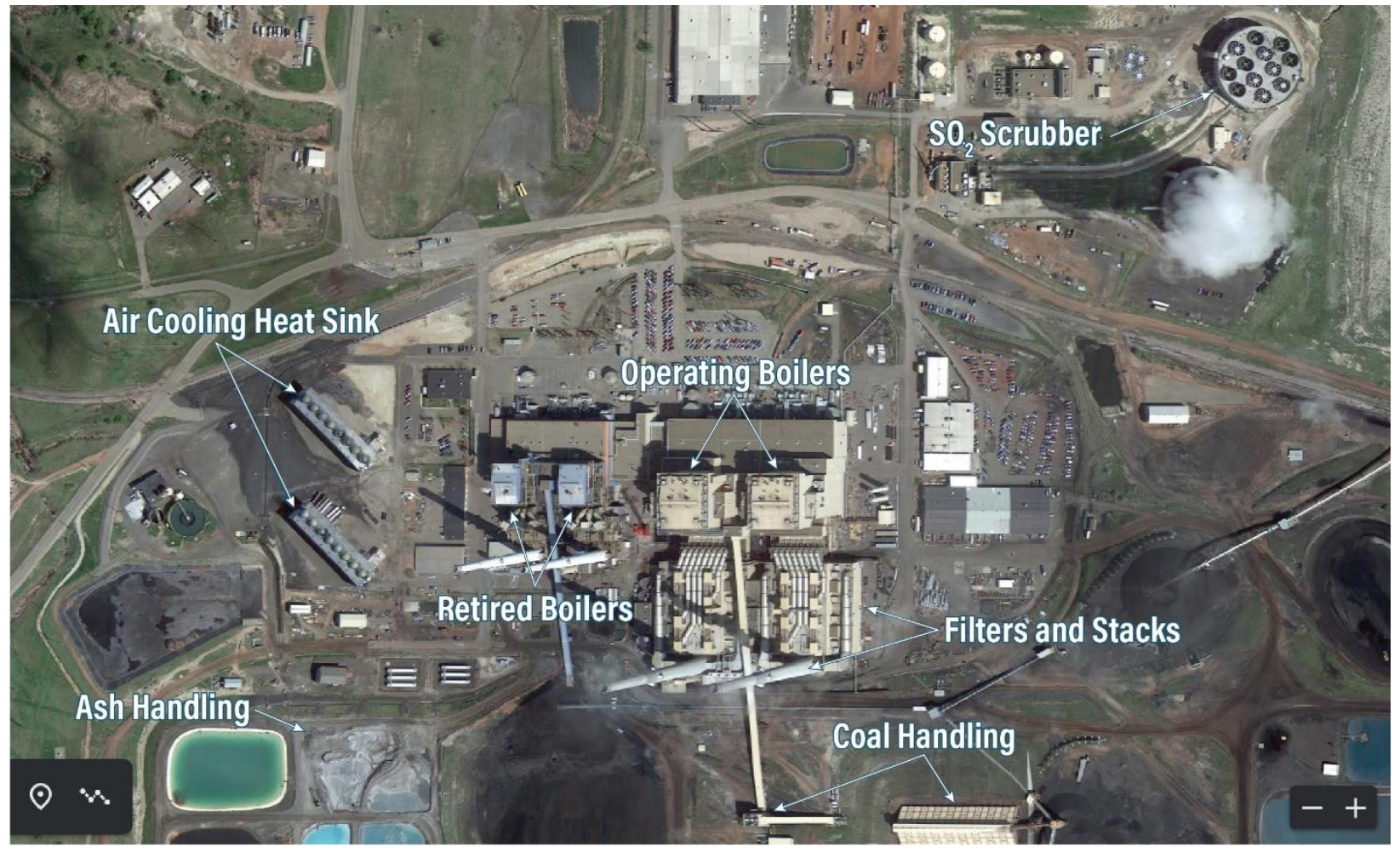

Figure 7. Colstrip power plant.

\subsection{Removing Coal Equipment}

Coal-specific equipment from the plant must be removed to clear the site in all scenarios. The removal should recover any remaining value of the equipment and clean the site environmentally. The removed equipment will include at least the coal, coal-storage facilities, coal-handling equipment, coal dryers and crushers, gas filters, ash-handling equipment, sulfur scrubbers, exhaust towers, and any ponds 
used in operation. This makes up approximately $75 \%$ of the original capital cost of the plant. ${ }^{25,31}$ The recovered value of the plant equipment was $5-15 \%$ in example plants decommissioned in $2014 .^{25,27}$ The removal of the two shutdown $358 \mathrm{MWe}$ coal plants introduces all the issues of coal decommissioning. Based on experience, full decommissioning of the two older plants at $\$ 400,000 / \mathrm{MWe}$ would cost approximately $\$ 143$ million. ${ }^{27}$ The removed equipment surrounds the coal boiler and frees up significant space on the site. The opened space should be fully restored to minimize required monitoring and eliminate any contaminants that would complicate reactor operation.

\subsection{Removing Coal Boiler}

With the coal-handling equipment removed; the site is considerably simplified. The remaining equipment centers on the boiler and turbine systems. Using one or more high-temperature nuclear reactors offers the potential to drive the high-temperature and pressure turbine system currently located at Colstrip.

A high-temperature nuclear reactor is a significantly different heat producer than a coal boiler, with its combustion process. A boiler redesign would be necessary, and the number of changes required and the uncertainty in the final performance make the use of the existing boiler difficult. The existing boiler includes multiple loops that optimize steam quality and efficiency in driving the turbine. The use of heat storage in molten-salt pools, for example, has been proposed ${ }^{77}$ and offers a chance to optimize turbine performance and a separate nuclear-quality high-temperature reactor loop. This partially separates the nuclear and power-generation parts of the plant.

Retaining the turbine would potentially save approximately $5.5 \%$ of the cost of the original plant. ${ }^{31}$ Reheating and preheating loops from the coal boiler would need to be replaced in the nuclear reactor's heat-transfer system. Given the uncertainty in the engineering outcome and potential cost in efficiency, benefits from directly using the boiler system are unlikely.

Beyond the direct matching of the components, an NRC license would be required. This currently requires a full understanding of the condition of the plant and its effects on nuclear safety. The condition information has not been established and approval of a partially repurposed plant has not been demonstrated.

\subsection{Removal of Entire Power Block}

Removal of the entire power block clears the plant for the new NPP and allows direct construction of a standard NPP. Retention of the electrical connection maximizes the directly reusable power transmission on the site. A recent coal-plant sale valued the electrical switchyard at $\$ 225$ million. ${ }^{78}$ The deployment of the NPP would benefit from the characterized and refreshed site.

Retention of the coal plant water supply would simplify the deployment of the replacement SMR. Colstrip pulls water from 30 miles away; a local lake stores the water. The water rights and access to the water system are assumed for the new NPP. Having provided long-term successful cooling of the coal plants, the system should be capable of supplying the NPP. Service water and ultimate-heat-sink water would need a design basis to support the NPP. Designs without safety-related water use would be able to use the water supply more confidently or less expensively.

Retention of previous buildings for engineering, management, maintenance, and storage further enhances the benefits of the plant site. Retention of medical, emergency, and firefighting capabilities can also potentially benefit the new SMR. The Colstrip power plant with a new generic NPP is shown in Figure 8. The significant simplification and reduced footprint of a NPP is shown. 


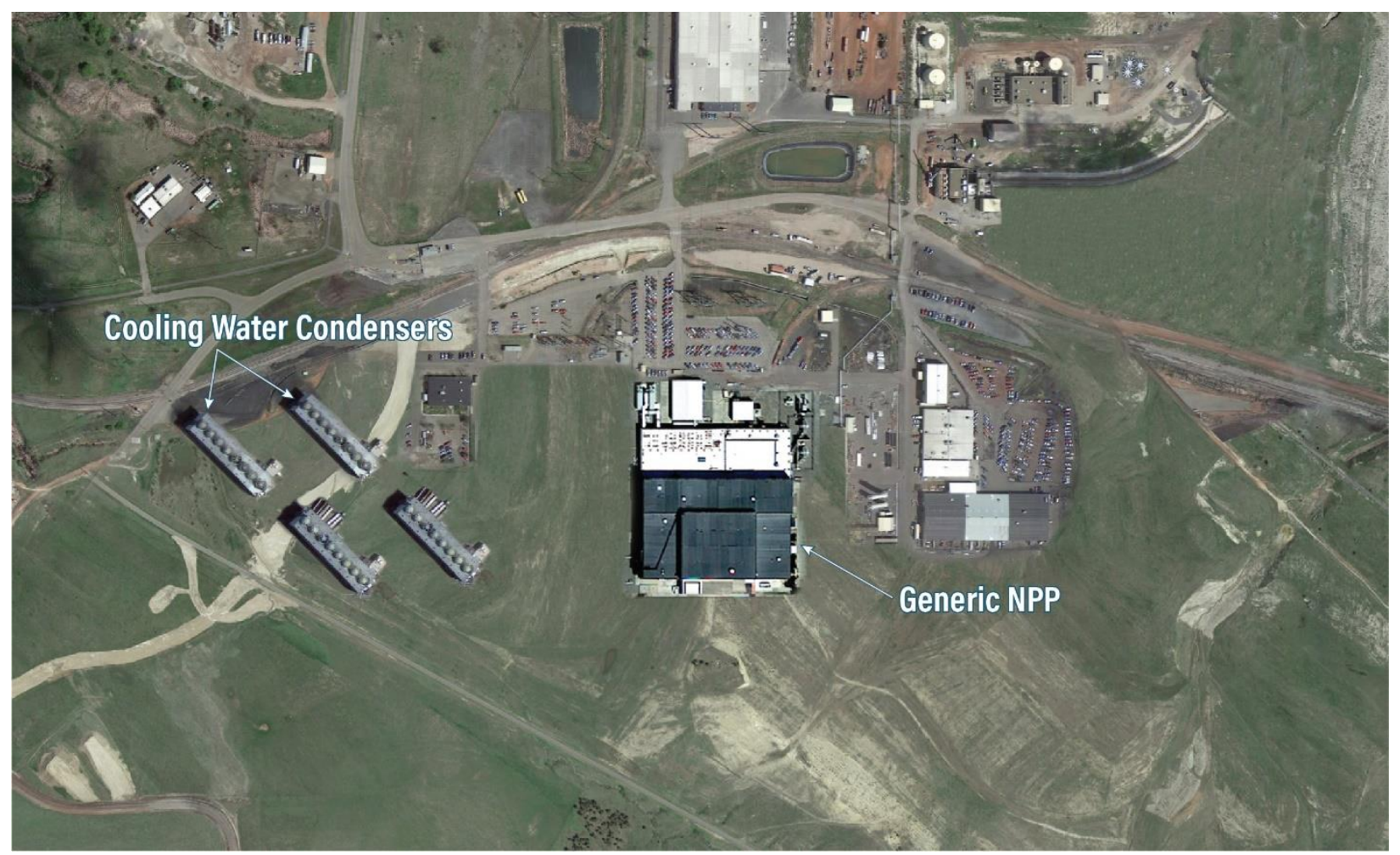

Figure 8. Colstrip Plant with generic NPP simulated.

\subsection{Starting with a Decommissioned and Cleared Site}

The most direct repowering option would be to completely decommission the Colstrip power plant to a cleared site and then repower the plant, allowing for optimized site cleanup. This would also allow for the information gained in decommissioning a CPP to be incorporated into transition plans. Based on the 2,272 MWe capacity on site, an estimated total cost for complete plant decommissioning would be above $\$ 900 \mathrm{M}$ and would provide flexibility on site use after decommissioning.

The time spent decommissioning the site would allow time for needed SMR site characterization and deployment planning. Using new equipment and nuclear design-basis systems would simplify the NRC application and fit well with a nuclear system vendor.

Even in a decommissioned and cleared site scenario, the water system and some commercial buildings could potentially be used. The Colstrip plant-repowering plan potentially lies between retaining power-block structure and a brown-field option. Understanding the environmental condition of the plant would help reduce the variability in the estimated cost. The specific plant technology will also influence the options available.

\subsection{Case-Study Summary}

The Colstrip plant is a potential location for a coal-to-nuclear transition. The coal-to-nuclear transition project has several factors that are attractive. The community depends highly on the power plant and mine for jobs and tax base, so a transition to a NPP should be positively received by the community. The owners of the plant are looking to reduce the carbon footprints of their companies. The site provides ample room for a new NPP and required equipment. The large space available allows additional industrial applications to support an integrated or embedded energy system to be incorporated. The site appears potentially suitable for a NPP; a seismic safety evaluation could be the most-significant environmental issue to be evaluated. The high electrical capacity of the site can accommodate a variety of NPPs on the 
site. Regulators and the state of Montana appear receptive to replacing a CPP with a NPP. Owners of the plant have experience with both CPP and NPP operations and licensing.

The site could use evaluation of D\&D. This would establish timelines and costs and help eliminate unknowns for a NPP transition at the site. This report would reduce unknowns related to nuclear-siting considerations.

Overall, the Colstrip appears to be a potential candidate for a coal-to-nuclear transition. Evaluation of the replacement NPP technology would need to be considered to understand what options are available and desirable. This analysis would include total site power, siting requirements, options for the NPP design, and project schedule and costs.

\section{CONCLUSIONS}

Transitioning a CPP site to a NPP site provides a clean, firm, dispatchable form of electricity that can take advantage of the grid connection and power-plant requirements. Although different reactor designs provide different deployment considerations, some of the grid connection and cooling system from the CPP could potentially be reused. Even if the NPP is a direct replacement of the CPP, some of the infrastructure and the value of the site can be retained.

Other CPP equipment may be of use to the NPP. Some advanced reactors better match the temperatures and pressures of modern CPP steam systems. Advanced reactors exist over a range of power levels and can often be deployed in multiple units to match the decommissioned CPP power rating. The low power of some advanced reactors may allow effective replacement of smaller-than-expected CPP. Despite the high-temperature capabilities of some new reactors, the match between the new NPP and the existing CPP equipment will require significant work to make practical. Using a heat-storage unit may allow a separation of nuclear and conventional power systems.

The CPP's coal- and ash-handling, air-filtering, and flue-gas desulfurization systems of the CPP will all require $\mathrm{D} \& \mathrm{D}$. The simplest repowering solution would be to also remove the rest of the CPP powerproducing equipment. The switchyard would require review to ensure it retains value for the NPP. The value of any CPP power-producing equipment has dropped with the overall value of CPPs. Replacing a CPP completely with a NPP would make the repowering as direct as possible. Any retained equipment would require maintenance, analysis, and licensing work to ensure the equipment is suitable to support the NPP. The information and permits for a CPP can support NPP site characterization and licensing. The design basis, nuclear quality, operating conditions, and newer technology would limit potential CPP equipment reuse. The NPP may require extra cleanup to avoid radioactive coal-ash components from interfering with NPP operation.

Repowering a CPP with a NPP would also directly support the local community by maintaining jobs and the tax base. CPP-produced jobs would be replaced by equivalent or upgraded jobs at the NPP. The site cleanup and deployment construction would provide local benefits even before the NPP goes online. Continued operation and outages would support and maintain the local economy in the same manner as did the CPP.

\section{RECOMMENDATIONS}

Additional information should be collected to inform coal-to-nuclear projects. Creating a methodology for evaluating CPP sites is needed going forward to enable comparison of coal-to-nuclear scenarios and would allow stakeholders to learn from one proposed project to another. Meetings to develop cooperative projects should be held to expand participants. Specific power plants for a coal-tonuclear transition should be evaluated to identify essential features of the transition. The CPP plants selected could come with different power levels, ages, and market structures in different regions of the country. Market competitiveness and potential IESs can be studied as well. The option of included industrial processes and other generation resources will allow more optimized site solutions. 


\section{REFERENCES}

1 E. Whieldon. 2020 "Removal of carbon from power company goals, Path to net zero: $70 \%$ of biggest US utilities have deep decarbonization targets, S\&P Global Market Intelligence,

2 Form EIA-860 detailed data with previous form data (EIA-860A/860B), Schedule 3, "Generator Data" (Retired \& Canceled Coal Units Only), 2019.

3 R. Davis, et al. 2021. "Coal-Fired Power Plant Retirements in the US”, NBER Working Paper No 28949

4 U.S. Energy Information Administration, "Electricity Generating Capacity,” Electricity. https://www.eia.gov/electricity/archive/capacity/, last accessed 6/14/2021

5 U.S. Energy Information Administration, "How much carbon dioxide is produced when different fuels are burned?" Frequently Asked Questions (FAQs), https://www.eia.gov/tools/faqs/faq.php?id=73\&t=11, last accessed 6/28/2021

6 https://www.eia.gov/energyexplained/nuclear/us-nuclear-industry.php last accessed 6/28/2021

7 https://www.nei.org/fundamentals/nuclear-provides-carbon-free-energy last accessed 7/14/2021

8 https://www.nei.org/fundamentals/nuclear-fuel last accessed 7/14/2021

9 https://www.nei.org/news/2019/what-happens-nuclear-waste-us last accessed: 7/14/2021

10 ADVANCED NUCLEAR REACTOR TECHNOLOGY, A PRIMER, Nuclear Innovation Alliance, September 2021

11 https://www.eia.gov/energyexplained/nuclear/nuclear-power-plants-types-of-reactors.php 6/30/2021

$12 \mathrm{https://world-nuclear.org/information-library/nuclear-fuel-cycle/nuclear-power-reactors/nuclear-}$ power-reactors.aspx 6/30/2021

13 https://www.nei.org/fundamentals/how-a-nuclear-reactor-works last accessed: 7/20/2021

14 https://www.energy.gov/ne/nuclear-reactor-technologies last accessed: 9/21/2021

15 Charles E. Stevenson. The EBR-II fuel cycle story. La Grange Park, Ill., USA: American Nuclear Society, 1987.

16 https://www.power-technology.com/projects/natrium-reactor-demonstration-project-wyoming-us/, last accessed: 11/10/2021

17 https://www.terrestrialenergy.com/technology/versatile/, last accessed: 11/10/2021

18 Advances in Small Modular Reactor Technology Developments A Supplement to: IAEA Advanced Reactors Information System (ARIS) 2020 Edition

19 R. Davis, J.S. Holladay, C. Sims, Coal-Fired Power Plant Retirements in the U.S., NBER Working Paper Series, June 2021

20 T. W. Kerlin, "HTGR Steam Generator Modeling," NUREG TM-1, July 1976

21 https://en.wikipedia.org/wiki/Supercritical_steam_generator, last accessed: 9/28/21

22 https://www.energy.gov/eere/geothermal/geothermal-power-plants-minimizing-land-use-and-impact, last accessed: 11/10/2021 
23 S. Ansolobehere, J. Beer, J. Deutch, A.D. Ellerman, J. Friedman, H. Herzog, H. Jacoby, P. Joskow, G. McRae, R. Lester, E. Moniz and E. Steinfeld. 2007 "The Future of Coal: Options for a CarbonConstrained World, an interdisciplinary MIT study," MIT Interdisciplinary Study Report, Massachusetts Institute of Technology, Cambridge, MA.

24 Nuclear Regulatory Commission, AP1000 Control Document, Chapter 5, "Reactor Coolant System and Connected Systems," Table 5.1-2. https://www.nrc.gov/docs/ML0715/ML071580904.pdf

25 D. Raimi. 2017. "Decommissioning U.S. Power Plants Decisions, Costs, and Key Issues, Resources for the Future Report."

26 https://www.utilitydive.com/news/think-closing-power-plants-is-less-risky-than-opening-them-thatsa-mistak/559915/ last accessed: 9/28/21

27 Sargent and Lundy, New Coal-Fired Power Plant Performance and Cost Estimates, S1-009808, August 28, 2009.

28 Transmission Cost Estimation Guide - MTEP19, MISO 2019

29 J. Eto. 2016. "Building Electric Transmission Lines: A Review of Recent Transmission Projects," Energy Analysis and Environmental Impacts Division Lawrence Berkeley National Laboratory.

30 T. Mason, T. Curry, and D. Wilson. 2012 "Capital Costs for Transmission and Substations: Recommendations for WECC Transmission Expansion Planning," Black and Veatch, October 2012. https://www.wecc.org/reliability/1210_bv_wecc_transcostreport_final.pdf last accessed: 6/28/2021.

31 D. Schlissel, A. Smith and R. Wilson. 2008.“Coal-Fired Power Plant Construction Costs, Synapse Energy Economics, INC, 2008.

32 “\$1.2 Billion Coal-Fired Power Plant Written Off as Worthless," 18 December 2020. https://bestpractice.biz/1-2-billion-coal-fired-power-plant-written-off-as-worthless, last accessed: $7 / 20 / 2021$.

33 "Brand new Dutch coal plants are crashing in value," Climate Home News, 30 November 2016. https://www.climatechangenews.com/2016/11/30/brand-new-dutch-coal-plants-are-crashing-invalue/, last accessed: 7/20/2021

34 https://www.spglobal.com/marketintelligence/en/news-insights/latest-news-headlines/us-powergenerators-set-for-another-big-year-in-coal-plant-closures-in-2020-56496107 last accessed: $7 / 20 / 2021$.

35 https://www.powermag.com/securitization-a-useful-financing-tool-for-transition-from-coal/, last accessed: 7/22/2021

36 "Well-Planned Retirement: Keys to Successful Coal Plant Decommissioning," Power, 2 January 2020. https://www.powermag.com/well-planned-retirement-keys-to-successful-coal-plantdecommissioning/ last accessed: 7/22/2021.

37 D. Blake, et al. 2003. "Overview on use of a Molten Salt HTF in a Trough Solar Field," NREL Parabolic Trough Thermal Energy Storage Workshop Golden, CO, NREL/PR-550-40028

38 https://www.terrapower.com/our-work/natriumpower, last accessed: 11/23/2021.

39 U.S. Nuclear Regulatory Commission. https://www.nrc.gov/reading-rm/doccollections/nuregs/brochures/br0298/index.html, last accessed: 6/28/2021

40 U.S. Environmental Protection Agency, 2020. "Cleaner Power Plants," Mercury and Air Toxics Standards, 23 October 2020. https://www.epa.gov/mats/cleaner-power-plants last accessed: 6/28/21 
41 U.S. Energy Information Administration. 2020. "Nuclear Explained: Nuclear power and the environment". https://www.eia.gov/energyexplained/nuclear/nuclear-power-and-the-environment.php last accessed: $6 / 28 / 21$

42 Nuclear Regulatory Research Regulatory Guide 4.11. 2012. "Terrestrial Environmental Studies for Nuclear Power Stations," Revision 2.

43 U.S. Environmental Protection Agency. 2021. "Radioactive Wastes from Coal-fired Power Plants," RadTown, 12 July 2021. https://www.epa.gov/radtown/radioactive-wastes-coal-fired-power-plants last accessed: 7/19/2021.

44 https://www.epa.gov/coalash/coal-ash-basics, last accessed: 10/28/2021.

45 DRAFT Pre-application Engagement to Optimize Advanced Reactors Application Reviews, NRC, 2021. https://adamswebsearch2.nrc.gov/webSearch2/main.jsp?AccessionNumber=ML20281A761.

46 D. Bradish. 2008. "NEI Fact Sheet on Water Consumption at Nuclear Power Plants, NEI Nuclear Notes. http://neinuclearnotes.blogspot.com/2008/03/nei-fact-sheet-on-water-consumption-at.html last accessed: 7/19/2021.

47 U.S. Environmental Protection Agency. 2021. "Cooling Water Intakes." https://www.epa.gov/cooling-water-intakes, last accessed: 6/18/2021.

48 U.S. Energy Information Administration. 2016. "Capital Cost Estimates of Utility Scale Electricity Generating Plants.” November 2016.

https://www.eia.gov/analysis/studies/powerplants/capitalcost/pdf/capcost_assumption.pdf.

49 U.S. Nuclear Regulatory Commission. 2020. "Vogtle Readiness Group." https://www.nrc.gov/reactors/new-reactors/col-holder/vog/vogtle-readiness-group.html viewed $6 / 27 / 2021$.

50 World Nuclear Associates, 2016-2021. "Barakah 1, United Arab Emirates.”http://www.worldnuclear.org/reactor/default.aspx/BARAKAH-1, viewed 7/20/2021.

51 https://www.nuscalepower.com/benefits/cost-competitive, last accessed: 6/27/2021.

52 https://ies.inl.gov/SitePages/Home.aspx, last accessed: 6/27/2021.

53 L. Ambort. 2020. "Coal Plant Communities Seek a Just Economic Transition,” Institute for Local Self-Reliance. https://ilsr.org/coal-closure-communities-just-transition/, last accessed: 7/21/2021.

54 https://www.mtpr.org/montana-news/2020-01-06/its-like-losing-a-family-member-colstrip-powerplant-closes-2-units, last accessed: 7/21/2021.

55 Headwater Economics, "Coal Communities Lack Strong Transition Plans," https://headwaterseconomics.org/energy/coal/coal-communities-lack-strong-transition-plans/ last accessed: 7/21/2021.

56 "Coal and jobs in the United States," Global Energy Monitor Wiki, 5 May 2021. https://www.gem.wiki/Coal_and_jobs_in_the_United_States\#cite_note-trends-13.

57 Nuclear Energy Institute. 2021. "Jobs: A single nuclear power plant creates more jobs than any other type of energy generation facility." https://www.nei.org/advantages/jobs last accessed: 7/27/2021.

58 "Nuclear Plant Adds Workers for Refueling, Maintenance Work," U.S. News and World Report, 10 May 2021. https://www.usnews.com/news/best-states/washington/articles/2021-05-10/nuclear-plantadds-workers-for-refueling-maintenance-work last accessed: 7/27/2021. 
59 D. Carson, "Economic Loss, higher taxes worry Davis-Besse neighbors," Fremont News Messenger, 29 May 2018. https://www.thenews-messenger.com/story/news/local/2018/03/29/economic-losshigher-taxes-worry-davis-besse-neighbors/470620002/, last accessed: 7/21/2021.

60 https://www.uamps.com/Carbon-Free, last accessed: 8/22/2021.

61 G. Black and S. Peterson. 2019. "Economic Impact Report, Construction and Operation of a Small Modular Reactor Electric Power Generation Facility at the Idaho National Laboratory Site," Butte County, Idaho, Regional Economic Development for East Idaho (REDI)

62 NuScale SMR Technology. 2021. "An Ideal Solution for Repurposing U.S. Coal Plant Infrastructure and Revitalizing Communities," NuScale Power LLC.

63 https://www.nuscalepower.com/benefits/built-for-resilience, last accessed: 7/21/2021.

64 https://aris.iaea.org/, last accessed: 7/21/2021.

65 https://westmoreland.com/location/rosebud-mine-montana/, last accessed: 8/19/2021.

66 https://www.cityofcolstrip.com/index.php?option=com_content\&view=article\&id=72\&Itemid=1193, last accessed: 9/26/2021.

67 https://www.greatfallstribune.com/story/news/2019/08/03/colstrip-power-plant-seeks-keep-workersand-cheaper-coal/1911777001/, last accessed: 8/20/2021.

$68 \mathrm{https} / / /$ billingsgazette.com/news/state-and-regional/hundreds-of-colstrip-mining-jobs-at-stake-aspower-plant-owner-seeks-new-coal-supplier/article_5665808c-4580-5891-b474-136b7a1293a7.html, last accessed: 8/20/2021.

69 https://www.bbc.com/news/election-us-2020-55050347, last accessed: 8/20/2021.

70 J. Rienerm D. Raunum R. Glaser. 2021. "Coal Communities in Transition: A case Study of Colstrip, Montana, Resources for the Future".

71 https://www.powermag.com/coal-power-plant-post-retirement-options/, last accessed: 8/20/2021.

72 https://www.energy.gov/articles/doe-announces-1095-million-support-jobs-and-economic-growthcoal-and-power-plant, last accessed: 9/26/2021.

73 https://www.spglobal.com/platts/en/market-insights/latest-news/electric-power/021221-montanasenate-panel-oks-study-to-convert-colstrip-coal-plant-to-nuclear, last accessed: 9/23/2021.

74 https://www.nei.org/news/2015/land-needs-for-wind-solar-dwarf-nuclear-plants, last accessed: 9/21/2021.

75 https://www.nrc.gov/docs/ML1905/ML19053A433.pdf, last accessed: 10/6/2021.

76 https://www.nrc.gov/reactors/operator-licensing/licensing-process.html, last accessed: 8/20/2021.

77 https://wyomingadvancedenergy.com/wp-content/uploads/2021/07/Natrium-including-QApresentation-Rev054.pdf, last accessed: 7/21/2021

78 https://insideclimatenews.org/news/23072021/north-dakota-coal-minnesota-clean-energy-coal-creek/, last accessed: 6/26/2021.

\section{Appendix A: ongoing projects related to coal to nuclear transitions Introductory text on references}


Across the industry, there are several active projects underway that are either directly related to evaluating coal sites for potential nuclear power or parts of these projects will provide future useful insights.

- Southern Ohio Diversification Initiative (SODI), "Generic Design Support Activities for Advanced Reactors",

- Team: SODI, Electric Power Research Institute, Southern Nuclear, Orano Federal

Services, Orano Decommissioning Services, INL

○ Primary Point of Contact: Kevin Shoemaker, SODI

○ Project Value: $\$ 4.9 \mathrm{M}$

○ This project will

- Reuse of existing infrastructure and structures. The SODI team will review DOE EM's D\&D documents for the Portsmouth Site and based on modern advanced D\&D methods, identify potential infrastructure, structures or building foundations that could be reused for a future reactor.

- Update the EPRI Siting Guide for advanced reactors. The team members, led by EPRI, will engage advanced reactor companies to seek input to review and modify the siting guide.

- Develop a plant parameter envelope (PPE). The SODI team will review the current NEI guidance for PPE development to evaluate and make recommendations for advanced reactor technologies.

- Use existing data and NRC licenses. The SODI team will evaluate available data for potential reuse.

- Develop an Early Site Permit (ESP) template.

- Project Deliverables The following are major deliverables:

- Infrastructure reuse paper (first draft)

- D\&D review paper (first draft)

- Development of PPE based on review of Nuclear Energy Institute (NEI) PPE document

- Infrastructure utilization assessment (final report)

- D\&D review paper (final report)

- ESP template

- Anticipated completion: December 2022

- TerraPower Natrium Project

○ Team: TerraPower, GE-Hitachi, Bechtel

○ Project Value: \$4B

- This project will demonstrate the Natrium reactor, a sodium-cooled fast reactor that leverages of decades of development and design undertaken by TerraPower and its partner, GE-Hitachi. The high-operating temperature of the Natrium reactor, coupled with thermal energy storage, will allow the plant to provide flexible electricity output that complements variable renewable generation such as wind a solar. In addition, this project 
will establish a new metal fuel fabrication facility that is scaled to meet the needs of this demonstration program.

- TerraPower recently announced plans to build its Natrium reactor at a retiring coal plant in Kemmerer, Wyoming. This is an incredible opportunity for the state, which currently generates almost $90 \%$ of its electricity generation from fossil fuels.

○ Anticipated Completion: 2028

- TerraPraxis Repowering Coal

- Team: Bryden Wood, University of Buffalo, Southern Company, Simpson Gumpertz \& Heger, MIT, TVA, Microsoft, Duke, Energy Northwest, DTE Energy, Ontario Power, Dominion Energy, ThorCon, TerraPower, Terrestrial Energy, Kairos Power

○ Primary Point of Contact: Eric Ingersoll and Kirsty Gogan, TerraPraxis

- The purpose of the repowering coal project is to prime and enable a global supply chain by articulating and accelerating the high value and achievable proposition for 2 TW of existing word-wide coal capacity to be repowered by 2050 . The proposition must be affordable and economically justified to plant owners, their shareholders, and other investors. The proposition must articulate supply chain solutions which facilitate the pace and scale of implementation of 2 TW by 2050: an average rate of 100 GWe per year or converting 250 coal-fired power stations (400 MWe average) each year. This must include a viable high level licensing pathway for rapid global deployment at scale to be designed into the approach.

○ Anticipated Completion: 2022

- DOE Systems Analysis and Integration Campaign - Investigate Benefits and Challenges of Converting Retiring Coal Plants into Nuclear Plants

○ TEAM: Idaho National Lab, Argonne National Lab, and Oak Ridge National Lab

○ Primary Point of Contact: Brent Dixon, INL

○ Project Value: $\$ 300 \mathrm{~K}$

- Conduct a techno-economic analysis on the retiring coal plants in the U.S. that could accommodate similarly sized nuclear units and the benefits and challenges.

Decarbonization of the electricity grid might require retiring the current thermal generation (coal and natural gas), plants, depending on the availability and economics of carbon sequestration technologies. This analysis will investigate if some of the coal plant sites could be converted into nuclear plant sites. The analysis will include (1) siting analysis with OR-SAGE - how many of the current coal plants could be good candidates for conversion in the U.S.; (2) technology analysis - which nuclear technologies (power size, operating temperature, emergency planning zone (EPZ), etc.) would be the best candidates to replace the coal plants; (3) assessment of the benefits and challenges of siting an advanced reactor this way, rather than using a greenfield - specifically, cost saving and societal impacts (reduction in $\mathrm{CO} 2$, potential to maintain jobs, tax revenues to community, etc.)

- $\quad$ NEI Coal to Nuclear Task Force

- Team: NEI Members

○ Primary Point of Contact: Kati Austgen and Marty O’Neill, NEI 
- Purpose: Interest in deploying advanced nuclear reactors (ANRs) at coal/fossil sites that have been retired, or are slated for retirement, grew considerably in 2021. This task force will address related threshold regulatory and practical questions: Do the potential advantages (regulatory, economic, environmental, etc.) of siting ANRs at coal/fossil sites truly outweigh any potential challenges? If so, what specific actions can the industry take now (beyond ongoing generic initiatives) to facilitate the siting and licensing of ANRs at such sites?

○ Deliverables:

- NEI guidance document on Coal to Nuclear Siting

- Document assessment of how remediation versus non-remediation of the coal site impacts the complexity of the NRC's NEPA evaluation

- Document assessment of whether state-issued permits can be transferred from a coal plant to a nuclear plant and the restrictions of such a transfer (using a sample of five states: Wyoming, Colorado, Washington, Montana, and Nebraska)

- NEI guidance document on geotechnical screening of candidate sites

- Provide an efficient, generic process for geotechnical screening

- To be referenced in above NEI guidance document on Coal to Nuclear Siting

○ Anticipated Completion: Ongoing 